\title{
The analysis of bullwhip effect in supply chain based on hedging strategy compared with optimal order quantity strategy
}

\author{
Kosar Akhavan Chayjan ${ }^{\mathrm{a}}$, Masoud Rabbani ${ }^{\mathrm{a},{ }^{*}}$, Jafar Razmi $^{\mathrm{a}}$, Mohamad Sadegh Sangari ${ }^{\mathrm{b}}$ \\ ${ }^{a}$ School of Industrial Engineering, College of Engineering, University of Tehran, Tehran, \\ Iran; ${ }^{b}$ Fouman Faculty of Engineering, University of Tehran, Gilan, Iran.
}

\begin{abstract}
The bullwhip effect is one of the most important problems in the supply chain management. It can cause large inefficiency in supply chain. Although there are many researches about bullwhip effect, few studies have investigated this phenomenon caused by product price fluctuation. In this paper we consider a two-period supply chain consisting of one supplier, one wholesaler and one retailer. The wholesale price may increase greatly in the beginning of second period. If this happens, a large number of end customers will go to purchase the product from retailer. For managing the end customers' demands in the second period, we consider two ordering strategies available to the retailer including optimal order quantity strategy and hedging strategy with call option. For each strategy, we calculate the bullwhip effect ratio for two periods and compare the results. We found that the lower exercise price in hedging strategy compared with the wholesale price in the optimal order quantity strategy must not contribute to extra product purchase. The research provides new insights into how hedging strategy can reduce bullwhip effect.
\end{abstract}

Keywords: Bullwhip effect; hedging strategy; price fluctuation; panic buying.

\section{Introduction}

\footnotetext{
* Corresponding author

Tel: +982188350642

Fax: +9821 88350642

E-mail addresses and mobile numbers: k.akhavan@ut.ac.ir (K. Akhavan Chayjan), mrabani@ut.ac.ir (M. Rabbani); +989121403975, jrazmi@ut.ac.ir (J. Razmi); +989123386829, mssangari@ut.ac.ir (M. S. Sangari).
} 
A supply chain is defined as a system of suppliers, manufacturers, distributors, retailers, and customers in which material, financial, and information flows connect participants in both directions [1]. In the supply chain system, there are various forms of uncertainty. The "bullwhip effect" is short-hand term for a dynamical uncertainly phenomenon in supply chains [2]. The bullwhip effect is one of the most studied phenomena in supply chain management [3]. It is defined as "the amplification of demand (or order) variance, from customer to factory, as demand information passes back through the supply chain" [4]. The bullwhip effect can cause large inefficiencies in supply chains, for example providing poor service to customers, weak demand forecasting, the loss of income and customers, extra inventory capital in the entire chain of warehouses, can be mentioned [5]. In order to control or eliminate the bullwhip effect we must first understand its causes [6]. Lee et al. [7] introduced four basic causes of this phenomenon: (1) wrong demand forecasting; (2) grouping of orders into batches; (3) fluctuation in the products prices; and (4) corporate policies regarding shortage. In this paper, we focus on the bullwhip effect arising from price fluctuations.

The law of demand is one of the most fundamental concepts in economics. The quantity demanded rises as the price of the products falls [8]. The demand law is an inverse relationship between price and quantity demanded; all things being equal. But there are some exceptions. Namely, the quantity demanded increases with price [9]. They include Giffen goods, speculative goods, conspicuous goods, conspicuous necessities, future expectations about prices, demand for necessaries and customer's irrational behaviour [10]. The supply chain members would be faced with panic buying by these exceptions. People usually buy large amounts of product, known as panic buying or consumer hoarding, to avoid future shortage [11], to confer them a sense of security, comfort, momentarily escape, and alleviate stress [12], although the price has increased. They may be behavioral and emotional responses to scarcity [13], in realistic market, consumers make purchase decisions with respect to price, not only in 
the current period, but also in past and future periods [14]. The large fluctuations in price were driven by either large shortages or surpluses in capacity. The shortages were exacerbated by panic buying and over ordering that was followed by a sudden drop in demand [15]. Any panic buying could lead to problems such as bullwhip effect [16].

Panic buying has been frequently observed. For example, fears of a sharp rise in the price of toilet paper have prompted panic buying in Taiwan when toilet paper manufactures were expecting a 10 to $30 \%$ price rise [17]. In a short interval of time in September 2008, the price of different types of rice in Iran rise suddenly and simultaneously the demand of rice rises [18]. Also, we can refer to panic buying arising from price fluctuation on cotton market in October 2015 [19], cooking oil and flour in Perak in January 2008 [20], wheat in Middle Eastern and North African countries in August 2007 [21], everything from electronics to wine in Russia in December 2014 [22].

Recently, financial hedging has received growing attention in the operations management literature [23]. Hedging is the act of protecting oneself against futures loss [24]. It is defined as "involves taking counterbalancing actions so that, loosely speaking, the future value varies less over the possible states of nature. These counterbalancing actions involve trading financial instruments, including short-selling, futures, options, and other financial derivatives" [25]. The wise use of derivatives for hedging purposes allows for an effective reduction of price risk exposure [26]. Hedging is known as price insurance, risk shifting or risk transference function [24]. In order to protect against various risks derived from production, demand, and price, option contracts have been extensively used in many industries such as fashion apparel industry, food processing industry, and automobile industry [27]. According to a survey of large US nonfinancial firms, approximately $40 \%$ of responding firms routinely purchase options or futures contracts in order to hedge price risks [28]. 
We know the price fluctuation caused by panic buying and then the bullwhip effect. Panic buying is now a frequent occurrence in many countries after the recent COVID-19 pandemic especially. Also, we are witnessing an increase in the number of panic buying for different reasons in Iran. The number of articles related to panic buying suggests increasing attention towards consumer behaviour under extreme conditions. Financial hedging is an approach to the management of price fluctuations. Many researchers have worked on bullwhip effect and hedging independently. The motivation of this study is to propose a new approach based on hedging to control the bullwhip effect. In this paper, we analyse the bullwhip effect based on hedging strategy through call option contracts compared with optimal order quantity strategy. The organization of this paper is as follows: In section 2, we review the related literature. Section 3 illustrates problem description and section 4 presents the proposed model and describes its details. In section 5, bullwhip effect measures will be addressed and in section 6 , they will be compared. Section 7 shows numerical analysis. Finally, in section 8 , conclusions and managerial insights are discussed.

\section{Literature Review}

There have been numerous studies addressing the bullwhip effect in recent years. However, a few have investigated the bullwhip effect due to price fluctuation [29]. Also, the use of financial hedging appears to be increasing over the years. In this research, we consider the hedging role on control of bullwhip effect. Hence, in the following lines, we will only review the literature relevant to bullwhip effect and financial hedging.

\subsection{Bullwhip effect}

Lee et al. [7] show that price fluctuation can cause the bullwhip effect. Moyaux and McBurney [30] present that some of kinds of speculators are able to stabilize the price in a market and 
reduce the price fluctuations caused by the bullwhip effect. Ozelkan and Cakanyildirim [31] analyse the impact of procurement price variability in the upstream of a supply chain on the downstream retail prices. Due to the reverse direction of the price variability propagation (compared to the direction of the bullwhip effect in order variability), they referred this behaviour as the reverse bullwhip effect in pricing (RBP).

Rong et al. [16] study how pricing strategies affect the variability of customers' orders. They show when customer behaviour is sufficiently strategic; the customer order process under oneperiod correction (1PC) pricing strategy is more volatile than the capacity process.

Bolarin et al. [32] analyse the impact of the price fluctuations on the variability of orders along a traditional multilevel supply chain. They show the bullwhip effect appears. Su and Geunes [33] examine the bullwhip effect results from price fluctuations in a two-echelon supply chain with deterministic and price-sensitive demand. They provide numerical evidence that increased system profit can coexist with the bullwhip effect as a result of price promotions.

Ma et al. [34] present a price-sensitive demand model and first-order autoregressive pricing process. Their findings show the retailer should share its customer demand and price information with its upstream businesses. Also, the wholesaler should adopt end-demand and order information, especially when the product price sensitivity coefficient is large or the demand shocks are low.

Wang et al. [35] investigate the bullwhip effect, from a consumer behaviour perspective. They develop insights into the influence of consumer price forecasting behaviour on the bullwhip effect. Their results demonstrated that consumer price forecasting behaviour can reduce the bullwhip effect, especially when the consumer sensitivity to price changes is medium.

Ma et al. [36] offer insights into how the bullwhip effect in two parallel supply chains with interacting price-sensitive demands is affected in contrast to the situation of single product in a serial supply chain. 
Ma and Xie [37] focus on the dynamic pricing game of the duopoly air conditioner market with disturbance in demand. Their results also indicate that the bullwhip effect between the order quantity and the actual demand is weakened gradually along with the price adjustment.

Gao et al. [38] investigate the difference in bullwhip effects in online and offline retail supply chains and offer insights into how frequent price discounts in e-commerce influence the bullwhip effect in the online retail supply chain. Tai et al [39] demonstrate that bullwhip effect can be, under conditions, stronger or weaker than the case where the price is not considered.

Gamasaee and Fazel Zarandi [40] investigated the impact of joint demand, orders, lead time and pricing decisions on reducing bullwhip effect. Their paper results show significant reduction in bullwhip effect.

Adnan and Ozelkan [41] investigate the behaviour of the bullwhip effect with respect to the price adjustment speed and historical price discount sensitivity. Their results show that controlling price discount sensitivity is useful for supply chain companies.

Zanddizari et al. [42] model the concept of Distance to Loss (DL) by bullwhip effect. This concept is a function of the retailer's selling price, the manufacture's wholesale price, the end item's salvage value, the retailer's expected demand, and the retailer's variance of demand. Feng et al. [43] investigate the customer's order variability and the firm's profit under several representative heuristic pricing strategies. They find that the bullwhip effect or reverse bullwhip effect can occur as a consequence of supply dramatic shock and adjusting the prices simultaneously.

Qu and Raff [44] show that a decentralized supply chain may be more resilient to demand shocks than a vertically integrated supply chain. Their results present that adjusting the wholesale price is valuable when the bullwhip effect is most likely to occur and potentially most harmful for manufacturer. 


\subsection{Financial hedging}

Some empirical studies such as Allayannis and Weston [45], Carter et al. [46], Bannai et al. [47], Chen et al. [48], Treanor et al. [49], Brusset and Bertrand [50], Luo et al. [51], Swidan and Merkert [52], Merkert and Swidan [53] demonstrated that financial derivatives enhanced firms' financial performance. Alam and Gupta [54] find that firms engaged in hedging compared to non-hedgers have less volatility in firm's value.

Kallapur and Eldenburg [55] examine that operational hedging policies include strategies such enhancing business operation's flexibility, diversifying production lines and varying the combination of variable and fixed costs. Borensztein et al. [56] use a dynamic optimization model to quantify the potential welfare gains of hedging against commodity price risk for commodity-exporting countries. They show that hedging enhances domestic welfare through reducing export income volatility and decreasing the country's need to hold precautionary reserves.

Liu et al. [57] offer circumstances under which supply chain coordination could be reached. They provide practical insights to the manufacturer and retailer. Tauser and Cajka [58] focus on selected aspects of risk management in agricultural business and compared different hedging methods which are relevant for managing the commodity risk associated with agricultural production.

Turcic et al. [28] has greatly improved researcher's understanding of why and how individual firms should hedge. Yang et al. [59] introduce three coordinating option contracts led by the supplier to reduce the retailer's risk, where the call option contract can reduce the shortage risk, the put option contract can reduce the inventory risk and bidirectional option contract can reduce the bilateral risk.

Park et al. [60] examine a firm's production planning, pricing and financial hedging decisions under exchange-rate and demand uncertainty. 
Kouvelis et al. [61] studies the hedging of cash-flow risks in a bilateral supply chain of a supplier and manufacturer. They characterize the interaction of hedging decisions of the supply chain partners and the associated effects of market conditions, production efficiencies, and cash-flow correlation.

Kouvelis et al [62] consider a firm purchasing a storable commodity from a spot market with price fluctuations and access to an associated financial derivatives market. In these circumstance, they survey two types of hedging instruments and compare their performances. Liu and Wang [63] present a network equilibrium model for supply chain networks with strategic financial hedging. They consider multiple competing firms. The firms are exposed to commodity price risk and exchange rate risk and they can use futures contracts to hedge the risks.

$\mathrm{Hu}$ et al. [64] build a simple theoretical model to compare the implications of fuel financial hedge and operational fuel efficiency improvement on airlines' expected profit. They find that financial hedge is more efficient in reducing airlines' profit volatility/risk exposure, while operational improvement would generate a higher expected profit level when its effectiveness is sufficiently high. Hainaut [65] studies hedging strategies of crop harvest incomes with futures and options on indexes of cumulated average temperatures.

March et al. [66] investigate a supply chain in which the vendor can adopt two financial approaches as means for hedging stocks in order to reduce the commodity risk related to the high price fluctuations.

Although in recent years, the number of studies that consider supply chain management as well as financial fields is increasing, none of the published articles has examined the effect of hedging on the bullwhip effect. In fact, what is new to the present study is identifying what will happen to bullwhip effect ratio if the hedging strategy is applied. The current research has 
focused on hedging strategy compared with optimal order quantity strategy for calculating bullwhip effect ratio in two echelon supply chain.

\section{Problem Description}

We consider a two-period supply chain $[11,67]$ consisting of one supplier, one wholesaler and one retailer. The supplier manufactures a single product selling to the wholesaler. The wholesaler sells the product to the retailer then the retailer sells it to end consumers. We assume that there is a large population of end consumers in market. Also, we presume that the retailer will receive the order at the beginning of each period and the lead time is zero. In the first period, the product price is constant and at the beginning of second period, the product price may increase significantly, which is reasonable in many situations. In each period, the price is independent and identically distributed (i.i.d.) from a normal distribution with average $\mu$ and variance $\sigma^{2}$. If the product price increases greatly, a large number of end customers will purchase the product from the retailer. This is contrary to the law of demand and the reasons of this event were mentioned in the Introduction section. Therefore, demand is a dependent variable on the price of the product.

We assume that in the first period the initial inventory level is zero and the retailer orders the optimal order quantity from the wholesaler. At the end of the first period, the leftover products are carried over to the second period for sale and incur a holding cost. For managing the end customers' demands in the second period, there are two ordering strategies available to the retailer, which are optimal order quantity strategy and hedging strategy. The retailer uses the call option contract for long hedging strategy. This contract is concluded between the wholesaler and the retailer. We suppose shortage is not allowed and in the second period, the retailer can buy additional units from an emergency source at a higher price.

This study aimed to address the following research question: 
- "what are the results of hedging on the bullwhip effect ratio?"

According to the conditions listed above, for each period, we will calculate the retailer's optimal order with optimal order quantity strategy and hedging strategy and for these strategies the retailer's bullwhip effect is measured by the ratio of the order quantity variance, encountered by the wholesaler, to the demand variance, faced by retailer. The ratio values are compared to each other. This ratio has been employed by many researchers $[39,68,69,70,71]$. We also consider the retailer to be risk neutral. When the retailer is risk neutral, it chooses to maximize its own expected profit [57].

\section{The Proposed Model}

In this section, the retailer's optimal order quantities are determined by the optimal order quantity and the hedging strategy.

\subsection{Notations}

To develop the model, notations are summarized as follows.

- Sets

- $\quad t=\{1,2\}$ : Time periods; $(t=1$ shows the first period and $t=2$ presents the second period)

- $\quad i=\{1,2\}$ : Types of price changes; $(i=1$ presents the product price is constant or the small change price per unit is occurred and $i=2$ shows significant increase in price per unit is happened), (for $t=1, i \neq 2$ )

- $\quad j=\{1,2\}$ : Types of retailer's ordering decisions; $(j=1$ shows the retailer only uses an optimal order quantity strategy and $j=2$ shows the retailer uses hedging strategy), (for $t=1, j \neq 2$ ) 


\section{- Decision Variables}

- $\quad q_{t}^{i j}$ : The retailer's order quantity in the period $t$ under decision $j$ and price change $i$

- $\quad\left(q_{t}^{i j}\right)^{*}$ : The retailer's optimal order quantity in the period $t$ under decision $j$ and price change $i$

Also, by assumptions explained in the text, $q_{1}^{12}, q_{1}^{21}$ and $q_{1}^{22}$ are not defined.

\section{- Parameters}

- $\quad p_{t}$ : The spot price per unit in the period $t$

- $\quad p_{2}^{k}:$ The exercise price per unit in the second period

- $\quad \theta_{2}$ : The significant increase in the wholesale price per unit in the second period $\left(\theta_{2}>0\right)$

- $\varepsilon_{2}$ : The small change in the wholesale price per unit in the second period, $\left(\varepsilon_{2}\right.$ can be positive or negative or zero)

- $\quad w_{t}$ : The wholesale price per unit in not-hedging in the period $t$

- $\varphi$ : The difference between the wholesale price and the exercise price per unit in the second period

- $\quad m_{t}$ : The retailer's fixed percentage profit margin in the period $t\left(m_{t}>0\right)$

- $\quad n_{2}$ : The emergency purchasing price per unit by the retailer in the second period

- $\quad c_{o 2}$ : The option price per unit in the second period

- $\quad h_{t}$ : The holding cost per unit in the period $t$

- $c_{t}$ : The order cost per unit in the period $t$

- $\quad \mu$ : The average of the product price in the period $t$

- $\sigma^{2}$ : The variance of the product price in the period $t$ 
- $\sigma$ : The standard deviation of the product price in the period $t$

- $\quad d_{1}$ : The product demand in the first period

- $\quad \mu_{d_{1}}$ : The end customer's average demand in the first period

- $\quad \sigma_{d_{1}}^{2}:$ The variance of the end customer's demand in the first period

- $\quad \sigma_{d_{1}}$ : The standard deviation of the end customer's demand in the first period

- $\quad d_{2}^{i}$ : The product demand in the second period under price change $i$

- $\quad \mu_{d_{2}^{i}}$ : The end customer's average demand in the second period under price change $i$

- $\quad \sigma_{d_{2}^{i}}^{2}$ : The variance of the end customer's demand in the second period under price change $i$

- $\quad \sigma_{d_{2}^{i}}$ : The standard deviation of the end customer's demand in second period under price change $i$

- $\quad r$ : Consumer sensitivity to price increases in the second period

- $\quad a$ : Basic market demand

- $\quad b:$ The demand curve slope

- $\quad f(x)$ : The probability distribution function of the end customer demand to the retailer

- $\quad F(x)$ : The cumulated distribution function of the end customer demand to retailer

- $\quad S\left(q_{t}^{i j}\right)$ : The retailer's expected sales in the period $t$ under decision $j$ and price change $i$

- $\quad I\left(q_{t}^{i j}\right):$ The expected leftover inventory in the period $t$ under decision $j$ and price change $i$ 
- $\quad H\left(q_{t}^{i j}\right)$ : The expected order quantity to the emergency source under decision $j$ and price change $i$

- $\quad \pi\left(q_{t}^{i j}\right)$ : The retailer's expected profit in the period $t$ under decision $j$ and price change $i$

- $\quad \bar{q}_{q_{1}^{i j}, q_{2}^{i j}}:$ The Total average retailer's order

- $\quad B W E_{q_{1}^{i j}, q_{2}^{i j}}$ : Bullwhip effect for the retailer's optimal order quantities under decision $j$ and price change $i,(i \neq 1)$.

$-\quad p_{2}^{k}<w_{2}<n_{2}<p_{2}$

\subsection{The relation between the wholesale price and the retail price}

The wholesaler is selling a product to the retailer at $w_{t}$ and the retailer is using a fixed percentage profit margin $\left(m_{t}>0\right)$ to identify $p_{t}$ [72]. The relation between $p_{t}$ and $w_{t}$ will be as formula (1).

$$
p_{t}=\left(1+m_{t}\right) w_{t}
$$

\subsection{Types of price Changes}

In the first period, $w_{1}$ is fixed. We have formula (2):

$$
p_{1}=\left(1+m_{1}\right) w_{1}
$$

At the beginning of the second period, the product price is constant or the small change price per unit $\left(\varepsilon_{2}\right)$ or significant increase $\left(\theta_{2}\right)$ in price per unit is occurred. Therefore, the relation between $w_{1}$ and $w_{2}$ will be as formula (3) and formula (4), respectively.

$$
w_{2}=w_{1}+\varepsilon_{2}
$$




$$
w_{2}=w_{1}+\theta_{2}
$$

By substituting formula (3) and formula (4) into formula (1), we will have formula (5) and formula (6) for second period:

$$
\begin{aligned}
& p_{2}=\left(1+m_{2}\right)\left(w_{1}+\varepsilon_{2}\right) \\
& p_{2}=\left(1+m_{2}\right)\left(w_{1}+\theta_{2}\right)
\end{aligned}
$$

\subsection{Types of demand model}

In this paper, the end customers' demand is considered as the product price function and is shown with linear function. For the first period, we consider the linear demand model as formula (7):

$$
d_{1}\left(p_{1}\right)=a-b p_{1}
$$

For the second period with constant product price or small change price per unit, we consider the linear demand model as formula (8):

$$
d_{2}^{1}\left(p_{2}\right)=a-b p_{2}
$$

For the second period, when significant increase in price per unit is happened, the linear demand model can be written as formula (9) [35]:

$$
d_{2}^{2}\left(p_{2}\right)=\left(a-b p_{2}\right)+r b\left(p_{2}-p_{1}\right), r>1
$$

In the formula (9), the first term on the right-hand side of the equation expresses the underlying demand and is a decreasing function of $p_{2}$, and the second term represents the impact of price behaviour on the demand. $p_{2}$ is higher than $p_{1}$, therefore, the customers buy more to reduce their future needs.

\subsection{The retailer's first period order quantity}

The retailer's first period expected profit is as formula (10): 


$$
\pi\left(q_{1}^{11}\right)=p_{1} S\left(q_{1}^{11}\right)-w_{1} q_{1}^{11}-h_{1} q_{1}^{11}-c_{1} q_{1}^{11}
$$

The linear demand model is as formula (11):

$$
d_{1}=a-b p_{1}
$$

The inverse demand equation will be as formula (12).

$$
p_{1}=\frac{1}{b}\left(a-d_{1}\right)
$$

Proposition 1. We substitute formula (12) in formula (10) and solve it for $q_{1}^{11}$. The retailer's first period optimal order quantity is given by:

$$
\left(q_{1}^{11}\right)^{*}=\mu_{d_{1}}+\sqrt{2 \pi} \sigma_{d_{1}}\left[\frac{1}{2}-\frac{w_{1}+h_{1}+c_{1}}{\frac{1}{b}\left(a-d_{1}\right)}\right]
$$

Proof: See Appendix 1.

\subsection{The retailer's second period order quantity}

At the beginning of second period, for purchasing product from wholesaler, the retailer will face one of two options about the product price:

- Constant price or small change price per unit $\left(\varepsilon_{2}\right)$

- $\quad$ Significant increase in price per unit $\left(\theta_{2}\right)$.

The retailer can use the optimal order quantity strategy or hedging strategy. The Figure 1 shows product price changes and the retailer ordering decisions in the second period.

[Figure 1]

Therefore, there are four scenarios. Table 1 shows these scenarios.

\section{[Table 1]}

In the second period, the retailer's ordering process is as shown in Figure 2. 
[Figure 2]

For each scenario, we calculate the retailer's optimal order quantity.

\section{- Scenario 1}

The retailer's expected profit is as formula (14):

$$
\pi\left(q_{2}^{11}\right)=p_{2} S\left(q_{2}^{11}\right)-w_{2} q_{2}^{11}-c_{2} q_{2}^{11}-h_{2}\left(q_{2}^{11}+I\left(q_{1}^{11}\right)\right)-n_{2} H\left(q_{2}^{11}\right)
$$

The linear demand model is as formula (15):

$$
d_{2}^{1}=a-b p_{2}
$$

The inverse demand equation will be as formula (16).

$$
p_{2}=\frac{1}{b}\left(a-d_{2}^{1}\right)
$$

Proposition 2. We substitute formula (16) in formula (14) and solve it for $q_{2}^{11}$. The retailer's optimal order quantity is given by:

$$
\left(q_{2}^{11}\right)^{*}=\mu_{d_{2}^{1}}+\sqrt{2 \pi} \sigma_{d_{2}^{1}}\left[\frac{1}{2}-\frac{w_{2}+c_{2}+h_{2}}{\frac{1}{b}\left(a-d_{2}^{1}\right)+n_{2}}\right]
$$

Proof: See Appendix 2.

\section{- Scenario 2}

The retailer's expected profit is as formula (18):

$$
\pi\left(q_{2}^{21}\right)=p_{2} S\left(q_{2}^{21}\right)-w_{2} q_{2}^{21}-c_{2} q_{2}^{21}-h_{2}\left(q_{2}^{21}+I\left(q_{1}^{11}\right)\right)-n_{2} H\left(q_{2}^{21}\right)
$$

The linear demand model is as formula (19):

$$
d_{2}^{2}=\left(a-b p_{2}\right)+r b\left(p_{2}-p_{1}\right)
$$

By substituting formula (2) and formula (6) into formula (19), we have formula (20):

$$
d_{2}^{2}=\left(a-b p_{2}\right)+\left[\left(m_{2}-m_{1}\right) w_{1}+\left(1+m_{2}\right) \theta_{2}\right] r b
$$

The inverse demand equation will be as formula (21):

$$
p_{2}=\frac{1}{b}\left(a+\left[\left(m_{2}-m_{1}\right) w_{1}+\left(1+m_{2}\right) \theta_{2}\right] r b-d_{2}^{2}\right)
$$


Proposition 3. We substitute formula (21) for $p_{2}$ in formula (18) and solve it for $q_{2}^{21}$. The retailer's optimal order quantity is given by:

$$
\left(q_{2}^{21}\right)^{*}=\mu_{2}^{2}+\sqrt{2 \pi} \sigma d_{2}^{2}\left[\frac{1}{2}-\frac{w_{2}+c_{2}+h_{2}}{\left[\frac{1}{b}\left(a+\left[\left(m_{2}-m_{1}\right) w_{1}+\left(1+m_{2}\right) \theta_{2}\right] r b-d_{2}^{2}\right)\right]+n_{2}}\right]
$$

Proof: See Appendix 3.

\section{- Scenario 3}

The retailer's expected profit is as formula (23):

$$
\pi\left(q_{2}^{12}\right)=p_{2} S\left(q_{2}^{12}\right)-w_{2} q_{2}^{12}-c_{2} q_{2}^{12}-c_{o 2} q_{2}^{12}-h_{2}\left(q_{2}^{12}+I\left(q_{1}^{11}\right)\right)-n_{2} H\left(q_{2}^{12}\right)
$$

The linear demand model is as formula (24):

$$
d_{2}^{1}=a-b p_{2}
$$

The inverse demand equation will be as formula (25):

$$
p_{2}=\frac{1}{b}\left(a-d_{2}^{1}\right)
$$

Proposition 4. We substitute formula (25) for $p_{2}$ in formula (23) and solve it for $q_{2}^{12}$. The retailer's optimal order quantity is given by:

$$
\left(q_{2}^{12}\right)^{*}=\mu_{d_{2}^{1}}+\sqrt{2 \pi} \sigma_{d_{2}^{1}}\left[\frac{1}{2}-\frac{w_{2}+c_{2}+c_{o 2}+h_{2}}{\frac{1}{b}\left(a-d_{2}^{1}\right)+n_{2}}\right]
$$

Proof: See Appendix 4.

\section{- Scenario 4}

The retailer's expected profit is as formula (27):

$$
\pi\left(q_{2}^{22}\right)=p_{2} S\left(q_{2}^{22}\right)-p_{2}^{k} q_{2}^{22}-c_{o 2} q_{2}^{22}-h_{2}\left(q_{2}^{22}+I\left(q_{1}^{11}\right)\right)-n_{2} H\left(q_{2}^{22}\right)
$$

The linear demand model is as formula (28): 


$$
d_{2}^{2}=\left(a-b p_{2}\right)+r b\left(p_{2}-p_{1}\right)
$$

By substituting formula (2) and formula (6) into formula (28), we have formula (29):

$$
d_{2}^{2}=\left(a-b p_{2}\right)+\left[\left(m_{2}-m_{1}\right) w_{1}+\left(1+m_{2}\right) \theta_{2}\right] r b
$$

The inverse demand equation will be as formula (30):

$$
p_{2}=\frac{1}{b}\left(a+\left[\left(m_{2}-m_{1}\right) w_{1}+\left(1+m_{2}\right) \theta_{2}\right] r b-d_{2}^{2}\right)
$$

Also, The relation between $p_{2}^{k}$ and $w_{2}$ will be as formula (31).

$$
w_{2}=p_{2}^{k}+\varphi
$$

Proposition 5. We substitute formula (30) for $p_{2}$ in formula (27) and solve it for $q_{2}^{22}$.

The retailer's optimal order quantity is given by:

$$
\left(q_{2}^{22}\right)^{*}=\mu_{d_{2}^{2}}+\sqrt{2 \pi} \sigma_{d_{2}^{2}}\left[\frac{1}{2}-\frac{p_{2}^{k}+c_{o 2}+h_{2}}{\frac{1}{b}\left(a+\left[\left(m_{2}-m_{1}\right) w_{1}+\left(1+m_{2}\right) \theta_{2}\right] r b-d_{2}^{2}\right)+n_{2}}\right]
$$

Proof: See Appendix 5.

Table 2 shows the retailer's optimal quantities for each scenario in the second period.

[Table 2]

\section{Bullwhip Effect Measures}

In the previous section, the retailer's optimal order quantity under the optimal order quantity strategy and hedging strategy were calculated. In this section, we develop expressions for bullwhip effect under the two strategies. The bullwhip effect ratio will be calculated according to $q_{1}^{11}$ and $q_{2}^{21}$. We then repeat the process for $q_{1}^{11}$ and $q_{2}^{22}$. Next, the results will be compared to each other. It should be noted that for second period, we consider only scenario 2 and scenario 4 because the product price increase occurred in these scenarios. 
To quantify the bullwhip effect, we can use the formula (33) that $\sigma_{o}^{2}$ shows variance of retailer order quantity, and $\sigma_{D}^{2}$ is variance of end customer demand.

$$
B W E=\frac{\sigma_{o}^{2}}{\sigma_{D}^{2}}
$$

Based on the preceding assumption, we can conclude that:

$$
\operatorname{Cov}\left(d_{1}, d_{2}^{i}\right)=0
$$

Before calculating the bullwhip effect ratio, we have the formula (35) and formula (36) as follow:

$$
\begin{aligned}
& \bar{q}_{q_{1}^{i j}, q_{2}^{i j}}=\frac{1}{2}\left(q_{1}^{i j}+q_{2}^{i j}\right) \\
& \sigma_{o}^{2}=\frac{1}{T-1} \sum_{t=1}^{T}\left(q_{t}^{i j}-\bar{q}_{q_{1}^{i j}, q_{2}^{i j}}\right)^{2}
\end{aligned}
$$

The variance of the market demand during the two periods can be written as formula (37):

$$
\sigma_{D}^{2}=\operatorname{Var}\left(d_{1}, d_{2}^{2}\right)=\sigma_{d_{1}}^{2}+\sigma_{d_{2}^{2}}^{2}+2 \operatorname{Cov}\left(d_{1}, d_{2}^{2}\right)=\sigma_{d_{1}}^{2}+\sigma_{d_{2}^{2}}^{2}
$$

According formula (11), we have formula (38) and formula (39) as follow:

$$
\begin{gathered}
\sigma_{d_{1}}^{2}=b^{2} \sigma^{2} \\
\sigma_{d_{1}}=b \sigma
\end{gathered}
$$

According formula (19) and formula (28), we have formula (40) and formula (41) as follow:

$$
\begin{gathered}
\sigma_{d_{2}^{2}}^{2}=\left(b^{2}+2 r^{2} b^{2}\right) \sigma^{2} \\
\sigma_{d_{2}^{2}}=\sqrt{\left(b^{2}+2 r^{2} b^{2}\right)} \sigma
\end{gathered}
$$

Therefore, according to formula (38) and formula (40), we have formula (42) as follow:

$$
\sigma_{D}^{2}=\left(2 b^{2}+2 r^{2} b^{2}\right) \sigma^{2}
$$

Also, according to formula (11), formula (15), formula (20) and formula (29), we have formula (43) and formula (44) as follow:

$$
\begin{aligned}
& \mu_{d_{1}}=\mu_{d_{2}^{1}}=a-b \mu \\
& \mu_{d_{2}^{2}}=a-b \mu+\left[\left(m_{2}-m_{1}\right) w_{1}+\left(1+m_{2}\right) \theta_{2}\right] r b
\end{aligned}
$$




\subsection{Bullwhip effect ratio for optimal order quantity strategy}

With substituting formula (35) and formula (36) in formula (33), we have formula (45) as follow:

$$
B W E_{q_{1}^{11}, q_{2}^{21}}=\frac{\sigma_{o}^{2}}{\sigma_{D}^{2}}=\frac{\left(q_{1}^{11}-\bar{q}_{q_{1}^{11}, q_{2}^{21}}\right)^{2}+\left(q_{2}^{21}-\bar{q}_{q_{1}^{11}, q_{2}^{21}}\right)^{2}}{\sigma_{D}^{2}}
$$

Theorem 1. The bullwhip effect for optimal order quantity strategy is as follow:

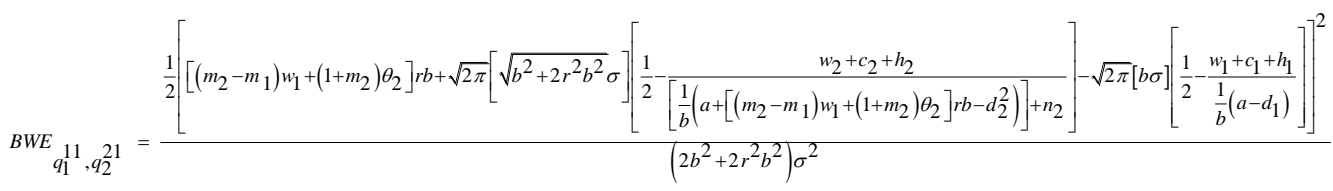

Proof: See Appendix 6.

Proposition 6. Bullwhip effect exists (i.e. $B W E_{q_{1}^{11}, q_{2}^{21}}>1$ ) if formula (47) hold.

$$
\begin{aligned}
& {\left[\left(m_{2}-m_{1}\right) w_{1}+\left(1+m_{2}\right) \theta_{2}\right] r b+1.25\left[\sqrt{b^{2}+2 r^{2} b^{2}} \sigma\right]+2.5[b \sigma]\left[\frac{w_{1}+h_{1}+c_{1}}{\frac{1}{b}\left(a-d_{1}\right)}\right]>} \\
& 2.5\left[\sqrt{b^{2}+2 r^{2} b^{2}} \sigma\right]\left[\frac{w_{2}+h_{2}+c_{2}}{\left[\frac{1}{b}\left(a+\left[\left(m_{2}-m_{1}\right) w_{1}+\left(1+m_{2}\right) \theta_{2}\right] r b-d_{2}^{2}\right)\right]+n_{2}}\right]+1.25[b \sigma]+\sqrt{2\left(2 b^{2}+2 r^{2} b^{2}\right)} \sigma
\end{aligned}
$$

Proof. See Appendix 7.

\subsection{Bullwhip effect ratio for hedging strategy}

According to formula (35) and formula (36), we have formula (48) as follow:

$$
B W E_{q_{1}^{11}, q_{2}^{22}}=\frac{\sigma_{o}^{2}}{\sigma_{D}^{2}}=\frac{\left(q_{1}^{11}-\bar{q}_{q_{1}^{11}, q_{2}^{22}}\right)^{2}+\left(q_{2}^{22}-\bar{q}_{q_{1}^{11}, q_{2}^{22}}\right)^{2}}{\sigma_{D}^{2}}
$$

Theorem 2. The bullwhip effect for hedging strategy is as follow:

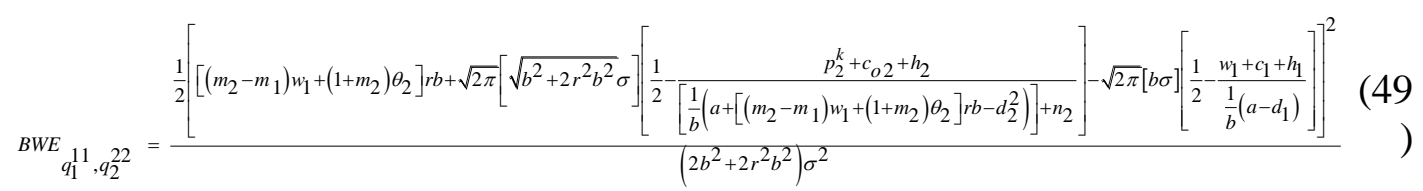

Proof: See Appendix 8.

Proposition 7. Bullwhip effect exists (i.e. $B W E_{q_{1}^{11}, q_{2}^{22}}>1$ ) if formula (50) hold. 


$$
\begin{aligned}
& {\left[\left(m_{2}-m_{1}\right) w_{1}+\left(1+m_{2}\right) \theta_{2}\right] r b+1.25\left[\sqrt{b^{2}+2 r^{2} b^{2}} \sigma\right]+2.5[b \sigma]\left[\frac{w_{1}+h_{1}+c_{1}}{\frac{1}{b}\left(a-d_{1}\right)}\right]>} \\
& 2.5\left[\sqrt{b^{2}+2 r^{2} b^{2}} \sigma\right]\left[\frac{p_{2}^{k}+h_{2}+c_{o 2}}{\left[\frac{1}{b}\left(a+\left[\left(m_{2}-m_{1}\right) w_{1}+\left(1+m_{2}\right) \theta_{2}\right] r b-d_{2}^{2}\right)\right]+n_{2}}\right]+1.25[b \sigma]+\sqrt{2\left(2 b^{2}+2 r^{2} b^{2}\right)} \sigma
\end{aligned}
$$

Proof. See Appendix 9.

\section{Comparison of the bullwhip effect ratios under different strategies}

In this section, we compare the bullwhip effect ratios for the optimal order quantity strategy and hedging strategy. To compare the bullwhip effect under the two retailer's ordering decisions in the second period, we deduce the following theorem:

Theorem 3. Let $B W E_{q_{1}^{11}, q_{2}^{22}}\left(B W E_{q_{1}^{11}, q_{2}^{21}}\right)$ be the bullwhip effect under hedging strategy (optimal order quantity strategy), assuming that the product price for two periods is i.i.d. from normal distribution. If we have $c_{o 2}>c_{2}+\varphi$, Then

$$
B W E_{q_{1}^{11}, q_{2}^{22}}<B W E_{q_{1}^{11}, q_{2}^{21}}
$$

Proof. See Appendix 10.

From Theorem 3, we know that formula (51) depends on the following three parameters: the option price, $c_{o 2}$; the order cost in the second period, $c_{2}$; and the difference between the wholesale price and the exercise price in the second period, $\varphi$. We can explain Theorem 3 as follows. If the retailer expects that the wholesale price will increase greatly in the beginning of second period and it makes people rush to buy the product, the retailer could hedge against the price fluctuations with call option. But the lower exercise price $\left(p_{2}^{k}\right)$ compared with the wholesale price $\left(w_{2}\right)$ must not contribute to an extra product purchase by retailer. According to $c_{o 2}>c_{2}+\varphi$, formula (22) and formula (32), the retailer's optimal order with hedging 
strategy will be less than the retailer's optimal order with optimal order quantity strategy. From the theoretical perspective, it has been pointed out that for validity of formula (51), as $c_{2}+\varphi$ increases $c_{o 2}$ must increase. Totally, under problem description in section 3, when the retailer's optimal order under hedging strategy is less than the retailer's optimal order under optimal order quantity strategy, the bullwhip effect under hedging strategy $\left(B W E_{q_{1}^{11}, q_{2}^{22}}\right)$ is less than the bullwhip effect under optimal order quantity strategy $\left(B W E_{q_{1}^{11}, q_{2}^{21}}\right)$.

\section{Numerical analysis}

In the preceding sections, we have calculated the retailer's optimal orders and bullwhip effect measures under problem description in section 3 and then we have compared the bullwhip effect ratios for the optimal order quantity strategy and hedging strategy. In this section, we provide numerical experiments to show the results and illustrate the impact of changing the value of parameters on the bullwhip effect measures. This section consists of two parts. First, in section 7.1, we compare $d_{1}, d_{2}^{1}$ and $d_{2}^{2}$ and show why we considered $r>1$. Subsequently, in section 7.2, we contrast $B W E_{q_{1}^{11}, q_{2}^{22}}$ and $B W E_{q_{1}^{11}, q_{2}^{21}}$. We survey the impacts of changing option price $\left(c_{o 2}\right)$, difference between the wholesale price and the exercise price $(\varphi)$, customer sensitivity to price increase $(r)$, demand curve slope $(b)$, the significant increase in the wholesale price $\left(\theta_{2}\right)$ and the standard deviation of the product price $(\sigma)$ on $B W E_{q_{1}^{11}, q_{2}^{21}}$ and $B W E_{q_{1}^{11}, q_{2}^{22}}$ in subsection 7.2.1, subsection 7.2.2, subsection 7.2.3, subsection 7.2.4, subsection 7.2.5 and subsection 7.2.6 respectively. Also, we fixed $a=200, m_{1}=0.25, m_{2}=0.3, w_{1}=30$ , $p_{2}^{k}=29, c_{1}=3, c_{2}=4, h_{1}=1.8, h_{2}=2, n_{2}=43$ and $\mu=30$.

\subsection{Comparison between $d_{1}, d_{2}^{1}$ and $d_{2}^{2}$}


The end customers' demand in the first period $\left(d_{1}\right)$ and the second period $\left(d_{2}^{1}\right.$ and $\left.d_{2}^{2}\right)$ are shown in Figure 3. We varied the parameters $r$ and $b$ over the values $r \in\{0,0.1,0.2,0.3,0.4, \ldots, 2\}$ and $b \in\{1,2,3,4,5,6\}$. We computed the corresponding demands using formula (11), formula (15) or formula (24) and formula (19) or formula (28). $d_{2}^{1}$ (second period demand in scenario 1 and 3 ) is slightly smaller than $d_{1}$ because the changes of product price was not significant but based on formula (5), the retailer's fixed percentage profit margin in period $2\left(m_{2}\right)$ is bigger than period $1\left(m_{1}\right)$.

For $r>1, d_{2}^{2}$ (demands in scenario 2 and 4) is bigger than $d_{1}$ and $d_{2}^{1}$ which shows that end customer rush to buy due to a significant increase in product price. For $0<r<1, d_{2}^{2}$ is smaller than $d_{1}$ and $d_{2}^{1}$. For $r=1, d_{2}^{2}$ is equal to $d_{2}^{1}$. As a result, we only consider $r>1$

[Figure 3]

\subsection{Comparison between $B W E_{q_{1}^{11}, q_{2}^{21}}$ and $B W E_{q_{1}^{11}, q_{2}^{22}}$}

From Appendix 10, we know $\triangle B W E=B W E_{q_{1}^{11}, q_{2}^{22}}-B W E_{q_{1}^{11}, q_{2}^{21}}$. In this section, we survey the effect of parameter values changes on $\triangle B W E$.

\subsubsection{Option price $\left(c_{o 2}\right)$}

Figure 4 illustrate how $\triangle B W E$ changes with $c_{o 2}$ for different values of $\sigma$ when $b=4$ , $r=1.5, \theta_{2}=6$. From Figure 4 , it can be observed that for $c_{02}=11$, we have $\triangle B W E=0$. By increasing the option price, $c_{02}$, from 11 to $20, \Delta B W E$ will decrease because $\triangle B W E$ are negatively correlated with $c_{02}$. Also, for $c_{o 2} \in\{11,12,13, \ldots, 20\}$, when the standard deviation of the price rises from 0.5 to $1.5, \triangle B W E$ will continue to 
be negative but its value rises. For example, for $c_{02}=18$ and $\sigma=0.5,1,1.5$, the value of $\triangle B W E$ is $-2.0216,-1.0408$ and -0.7138 respectively. This means that the lower standard deviation of product price, the hedging strategy is better than the optimal order strategy to decrease bullwhip effect.

[Figure 4]

\subsubsection{Difference between the wholesale price and the exercise price $(\varphi)$}

Figure 5 illustrate how $\triangle B W E$ changes with $\varphi$ for different values of $\sigma$ when $b=4$, $r=1.5, \quad \theta_{2}=6$ and $c_{o 2}=20$. We consider $p_{2}^{k} \in\{21,22,23,24, \ldots, 29\}$, therefore, according formula (31), we have $\varphi \in\{7,8, \ldots, 15\}$. For this value, $\triangle B W E$ is negative but it increases while keeping $c_{o 2}$ constant. Because with increasing $\varphi$, the value of $c_{o 2}-(c+\varphi)$ decrease.

Also, for $\varphi \in\{7,8, \ldots, 15\}$, when the standard deviation of the price rises from 0.5 to 1.5, $\triangle B W E$ will continue to be negative and its value rises. This means that the lower standard deviation of product price, the hedging strategy is better than the optimal order strategy to decrease bullwhip effect.

[Figure 5]

\subsubsection{Consumer sensitivity to price increases $(r)$}

Figure 6 illustrate how $\triangle B W E$ changes with $r$ for different values of $\sigma$ when $b=4$, $\theta_{2}=6$ and $c_{o 2}=15$. We consider $r \in\{1,1,1,1.2, \ldots, 2\}$. By raising $r$, the value of $\triangle B W E$ decrease. This means when consumer sensitivity to price increases, the hedging strategy is better than optimal order quantity strategy to decrease bullwhip effect. By increasing standard deviation of product price, $\sigma$, and consumer sensitivity to price, $r$ 
, although $\triangle B W E$ will continue to be negative but its value rises. Namely, by increasing the product price fluctuation and end customer rushing, the hedging strategy is better than the optimal order quantity strategy but it will be less effective.

[Figure 6]

\subsubsection{The demand curve slope $(b)$}

Figure 7 illustrate how $\triangle B W E$ changes with $b$ for different values of $\sigma$ when $r=1.5$ , $\theta_{2}=6$ and $c_{o 2}=15$. We consider $b \in\{1,2,3, \ldots, 6\}$. Because from formula (12), formula (21) and formula (30), we know that the end customer demand is correlated with the slope of demand curve, $b$, negatively. This means that $b$ increases, the number of end customer demand decreases. By raising $b$, the value of $\triangle B W E$ decrease. Also, by raising the standard deviation, $\sigma$, and the slope of demand curve, $b$, the value of $\triangle B W E$ is negative, but its values increase. These show that the hedging strategy is better than optimal order strategy to decrease bullwhip effect.

[Figure 7]

\subsubsection{The significant increase in the wholesale price $\left(\theta_{2}\right)$}

Figure 8 illustrate how $\triangle B W E$ changes with $\theta_{2}$ for different values of $\sigma$ when $b=4$ , $r=1.5$, and $c_{o 2}=15$. We consider $\theta_{2} \in\{1,2,3, \ldots, 10\} . w_{2}$ varies directly as $\theta_{2}$ according to formula (4). When $\theta_{2}$ increases, $w_{2}$ increases and $\varphi$ also rises. While keeping $c_{o 2}$ constant and based on Theorem 3 , the value of $c_{o 2}-\left(\theta_{2}+\varphi\right)$ decreases and the difference between $B W E_{q_{1}^{11}, q_{2}^{21}}$ and $B W E_{q_{1}^{11}, q_{2}^{22}}$ is reduced. As a result, the value of $\triangle B W E$ rises. For $\theta_{2}=10$, we have $c_{o 2}=\left(\theta_{2}+\varphi\right)$ then $\triangle B W E=0$. Figure 8 presents 
it. Also, by rising the standard deviation, $\sigma$, the value of $\triangle B W E$ is negative, but its values increase.

[Figure 8]

\subsubsection{The standard deviation of the product price $(\sigma)$}

Figure 9 illustrate how $\triangle B W E$ changes with $\sigma$ when $b=4, r=1.5, \theta_{2}=6$ and $c_{o 2}=15$. We consider $\sigma \in\{0.5,0.6, \ldots, 1.5\}$. By increasing $\sigma$, the value of $\triangle B W E$ increases. This means that by raising the product price standard deviation, the hedging strategy is better than optimal order quantity strategy to decrease bullwhip effect but it will be less effective.

[Figure 9]

\section{Conclusions}

This paper introduces the hedging strategy for controlling bullwhip effect and compares it to optimal order quantity strategy. We derive analytical expressions for the bullwhip effect ratio under two strategies, the hedging strategy, and the optimal order quantity strategy. In the following section, we present the results. These results provide some useful managerial insights on the implementation of these strategies.

(1) When the product price fluctuations cause panic buying and it makes the bullwhip effect, the hedging strategy can help to control it. The retailer may use a long hedge to fix the good price and manage the bullwhip effect.

(2) If the option price $\left(c_{o 2}\right)$ is bigger than the sum of the order cost and the difference between the wholesale price and the exercise price $(c+\varphi)$, the hedging strategy is better than the optimal order quantity strategy for controlling the bullwhip effect. So in this case, purchasing through a hedging strategy will be more expensive than buying 
through an optimal order quantity strategy. It prevents the retailer from buying too much of the product. If the retailer buys over a certain amount of product just because it is cheap, and the intensity of customer demand decreases, the unsold products are carried over the next periods. This increases the bullwhip effect.

(3) The retailer's ordering behaviour is important when the product price has volatility. In this circumstance, the retailer buys its product by call option contract cheaper than other method and he should be careful about the order quantities. The lower exercise price in hedging strategy compared with the wholesale price in the optimal order quantity strategy must not contribute to the extra product purchase. A large amount of product may protect the retailer against the high fluctuations in the end customers' demand but increases the bullwhip effect ratio. Therefore, it is important to decide about ordering strategy and the order quantities when the product price has fluctuations or we expect it to be.

(4) The product price is one of the important factors that the end customers pay attention to it. Also, the retailers consider the price as the criterion for the sales strategy. Accurate price forecasting and predicting end customer behavior can help the retailer to choose the right ordering strategy. If the retailer correctly forecasts price increasing, the use of hedging strategy could help to control the bullwhip effect considerably.

(5) The price standard deviation is a statistical expression that gives an indicator of price fluctuations in the market. High price fluctuations can lead to unstable markets and the end customers' emotional decisions. The reason for these decisions is fear and greed. The high price standard deviation means high price volatility. In this situation, while $\left(c_{o 2}>c+\varphi\right)$ is established, for controlling the bullwhip effect, the hedging strategy is better than the optimal order quantity strategy but its effectiveness decreases.

(6) The bullwhip effect is not completely eliminated by hedging strategy. 
A summary of our findings indicates that bullwhip effect reduction is important when there are price fluctuations in markets and companies can use hedging strategy to decrease the bullwhip effect.

This paper recommends several future directions to add our understanding of the influence of hedging strategy on the bullwhip effect. First, our model considers only linear demand function; the other demand functions require further study. Second, this paper assesses only the optimal order quantity strategy comparing with hedging strategy; the other ordering strategy can be considered. Finally, extending the two-period supply chain to multi-period chains would be another contribution for the future studies.

\section{References}

1. Fiala, P., "Information sharing in supply chains", Omega 33(5), pp. 419-423 (2005).

2. Derbel, M., H. Chabchoub, W. Hachicha, and F. Masmoudi. "Measuring the impact of (s, S) ordering policy on the bullwhip effect by means of simulation optimization", Paper presented at International Conference on Advanced Logistics and Transport, May 29-31 (2013).

3. Braz, A. C., Mello, A. M., Gomes, L. A. V., and Nascimento, P. T. "The bullwhip effect in closed-loop supply chains: A systematic literature review". Journal of Cleaner Production 202, pp. 376-389 (2018).

4. Chatfield, D. C., Kim, J. G., Harrison, T. P., and Hayya, J. C. "The bullwhip effect- impact of stochastic lead time, information quality and information sharing: A simulation study". Production and Operation Management 13(4), pp. 340-353 (2004).

5. Sabbaghnia, A., and J. Razmi. "Tracing the impact of non-uniform forecasting methods on the severity of the bullwhip effect in two- and three- level supply chains". International Journal of Management Science and Engineering Management 10(4), pp. 1-8 (2015).

6. Chen, F., Z. Drezner, K. Ryan, and D. Simchi-Levi. "The bullwhip effect: managerial insights on the impact of forecasting and information on variability in a supply chain". Quantitative Models for Supply Chain Management 17, pp. 417-439 (1999).

7. Lee, H.L., V. Padmanabhan., and S. Whang. "The bullwhip effect in supply chains". Sloan Management Review 38(3), pp. 93- 102 (1997).

8. Frank, R. H. "Microeconomics and behaviour”. $7^{\text {th }}$ ed., pp. 28, McGraw-Hill Irwin (2008). 
9. Das, P. S. “Microeconomics for Business”. pp. 47, SAGE Publication: India. (2007).

10. Agarwal, S., K. “Business Economics”. pp. 41-43, New Delhi: S. Chand Publishing (2018).

11. Shou, B., H. Xiong, and Z. Shen. "Consumer Panic Buying and Quota Policy under Supply

Disruptions”. Working paper. Hong kong: City University of Hong Kong. (2013).

12. Yuen, K.F., Wang, X., Ma, F., and Li, K.X., "The psychological causes of panic buying following a health crisis". International Journal of Environmental Research and Public Health 17(10): 3513 (2020).

13. Sterman, J., and G. Dogan. "I'm just stocking up before the hoarders get here. Behavioral causes of phantom ordering in supply chains". Journal of Operations Management 39-40(1), pp. 6-22 (2015).

14. Ahn, H. S., Gumus, M., and Kaminsky, P. "Pricing and manufacturing decisions when demand is a function of prices in multiple periods". Operations Research 55, pp. 1039-1057 (2007).

15. Chopra, S., and P. Meindl. "Supply chain Management, Strategy, Planning, and Operation ", $6^{\text {th }}$ ed., pp. 262 Pearson. (2016).

16. Rong, y., Shen, Z.-J. M., and Snyder, L. "Pricing during disruptions a cause of reverse bullwhip effect”. SSRN Electronic Journal. (2009).

17. Euronews. "Panic buying 'toilet paper frenzy' in Taiwan." 2018. Accessed April 2019. https://www.euronews.com/2018/02/28/panic-buying-toilet-paper-frenzy-in-taiwan.

18. Makui, A., S. J. Sadjadi, and N. Karampour. "The Impact of Bullwhip Effect in Highly Volatile Market”. Journal of Industrial Engineering, University of Tehran, Special Issue: pp. 95-102 (2011).

19. Dawn. "Commodities: Panic buying on cotton market." 2019. Accessed August 2019. https://www.dawn.com/news/1492972/commodities-panic-buying-on-cotton-market.

20. Star online. "Panic buying and rumours of price increases blamed." 2008. Accessed July 2019. https://www.thestar.com.my/news/nation/2008/01/05/panic-buying-and-rumours-ofprice-increases-blamed.

21. Financial Times. "Panic buying sends wheat price to new highs." 2007. Accessed August 2019. https://www.ft.com/content/33d9f882-450e-11dc-82f5-0000779fd2ac.

22. ABC. "Russian currency crisis: Consumers panic buy in fear of price hikes; PM moves to assure ministers." 2014. Accessed August 2019. https://www.abc.net.au/news/2014-1218/russians-panic-buying-in-fear-of-price-hikes/5974620. 
23. Goel, A., and F. Tanrisever. "Financial Hedging and Optimal Procurement Policies under Correlated Price and Demand". Production and Operations Management 26(10), pp. 19241945 (2017).

24. Gupta, S. L.. "Financial Derivatives: Theory, Concepts and Problems”. PHI Learning Pvt. Ltd. 2th Edn., pp. 42, 216, Dehli (2017).

25. Tekin, M., and S. Ozekici. "Mean-Variance newsvendor model with random supply and financial hedging”. IIE Transactions 47(9), pp. 910-928 (2014).

26. Halkos, G., and Tsirivis, A., "Energy commodities: a review of optimal hedging strategies". Energies 12(20) 3979 (2019).

27. Wan, N., and Chen, X. "Multiperiodic procurement problem with option contracts under inflation". Mathematical Problems in Engineering 4, pp. 1-11 (2016).

28. Turcic, D., D. Kouvelis, and E. Bolandifar. "Hedging Commodity Procurement in a Bilateral Supply Chain”. Manufacturing \& Service Operations Management 17(2), pp. 221235 (2015).

29. Trapero, J. R., and D. J. Pedregal. "A novel time-varying bullwhip effect metric: An application to promotional sales". International Journal of Production Economics 182, pp. 465-471 (2016).

30. Moyaux T., and P. McBurney. "Reduction of the bullwhip effect in Supply Chains through Speculation. In: Bruun C. (eds) Advances in Artificial Economics". Lecture Notes in Economics and Mathematical Systems 584, pp. 77-89 (2006).

31. Ozelkan, E. C., and Cakanyildirim, M. "Reverse Bullwhip effect in pricing". European Journal of Operational Research 192(1), pp. 302-312 (2009).

32. Bolarin, F. C., Frutos, A. G., and Lise, A. "Assessing the impact of prices fluctuation on demand distortion whitin a multi-echelon supply chain". Traffic \& Transportation 23(2), pp. 131-140 (2011).

33. Su, Y., and Geunes, J. "Price promotions, operation cost, and profit in a two-stage supply chain”. Omega 40(6), pp. 891-905 (2012).

34. Ma, Y., Wang, N., Che, A., Huang, Y., and Xu. J. "The bullwhip effect under different information sharing settings: a perspective on price-sensitive demand that incorporates price dynamics”. International Journal of Production Research 51(10), pp. 3085-3116 (2013).

35. Wang, N., Ma, Y., He, Z., Che, A., Huang, Y., and Xu, J. "The impact of consumer price forecasting behaviour on the bullwhip effect". International Journal of Production Research 52(22), pp. 6642-6663 (2014). 
36. Ma, Y., Wang, N., He, Z., Lu, J., and Liang, H. "Analysis of the bullwhip effect in two parallel supply chains with interacting price-sensitive demands". European Journal of Operational research 243(3), pp. 815-825 (2014).

37. Ma, J., and Xie, L. "Study on the complexity pricing game and coordination of the duopoly air conditioner market with disturbance demand". Communications in Nonlinear Science and Numerical Simulation 32, pp. 99-113 (2015).

38. Gao, D., N. Wang, Z. He, and T. Jia. "The bullwhip effect in an online retail supply chain: A perspective demand based on the price discount in E-commerce". IEEE Transactions on Engineering Management 64(2), pp. 134-148 (2017).

39. Tai, P., Duc, T., and Buddhakulsomsiri, J. "Measure of bullwhip effect in supply chain with price-sensitive and correlated demand". Computers \& Industrial Engineering 127, pp. 408-419 (2018).

40. Gamasaee, R., Fazel Zarandi, M. H. "Incorporating demand, orders, lead time, and pricing decisions for reducing bbullwhip effect in supply chains". Scientia iranica E 25(3), pp. 17241749 (2018).

41. Adnan, Z., Ozelkan, E., "Bullwhip effect in pricing under different supply chain game structures", Journal of Revenue and Pricing Management, Palgrave Millan, 18(5), pp. 393-404 (2019).

42. Zanddizari, M., Tavakkoli-Moghaddam, R., Azaron, A. "Modeling stock-out loss and overstocking loss generated by bullwhip effect”. Scientia Iranica E 26(3), pp. 1913-1924 (2019).

43. Feng, X., Rong, Y., Shen, Z., Snyder, L., "Pricing during disruptions: order variability versus profit", Decision Sciences, (2020).

44. Qu, Z., Raff, H., "Vertical contracts in supply chain and bullwhip effect". Published Online: Management Science, (2020).

45. Allayannis, G., ihrig, J., and Weston, J. P. "Exchange-rate hedging: Financial versus operational strategies”. The American Economic Review 91(2), pp. 391-395 (2001).

46. Carter, D. A., Rogers, D. A., and Simkins, B. J. "Does hedging affect firm value? Evidence from the US airline industry”. Financial management 3(1), pp. 53-86 (2006).

47. Bannai, M., Tomita, Y., Ishida, Y., Miyazaki, T., Akisawa, A., and Kashiwagi, T. "Risk hedging against the fuel price fluctuation in energy service business". Energy 32(11), pp. 20512060 (2007).

48. Chen, J.H., and Lin, Z. "Developing an SVM based risk hedging prediction model for construction material suppliers". Automation in construction 19(6), pp. 702-708 (2010). 
49. Treanor, S. D., Rogers, D. A., Carter, A. C., and Simkins, B. J. "Exposure, hedging and value: New evidence from the U.S. airline industry". International Review of Financial Analysis 34, pp. 200-211 (2014).

50. Brusset, X., Bertrand, J. "Hedging weather risk and coordinating supply chains". Journal of Operations Management 64(1), pp. 41-52 (2018).

51. Luo, J., Zhang, X., Wang, C. "Using put option contracts in supply chains to manage demand and supply uncertainty". Industrial Management \& Data Systems 118(7), pp. 14771497 (2018).

52. Swidan, H., and Merkert, R. "The relative effect of operational hedging on airline operating costs”. Transport Policy 80, pp. 70-77 (2019).

53. Merkert, R., and Swidan, H. "Flying with(out) a safety net: Financial Hedging in the airline industry". Transportation Research Part E: Logistics and Transportation Review 127, pp. 206219 (2019).

54. Alam, N., Gupta, A., "Does hedging enhance firm value in good and bad times". International Journal of Accounting \& Information Management 26(1), pp. 132-152 (2018).

55. Kallapur, S., and Eldenburg, L. "Uncertainty, real options, and cost behaviour: Evidence from Washington state hospitals". Journal of Accounting Research 43, pp. 735-752 (2005).

56. Borensztein, E., Jeanne, O., and Sandri, D. "Macro-hedging for commodity exporters". Journal of Development Economics 101, pp. 105-116 (2013).

57. Liu, Z., Chen, L., Li, L., and Zhai, X. "Risk hedging in supply Chain: Option vs. price discount”. International Journal of Production Economics 151, pp. 112-120 (2014).

58. Tauser, J., and Cajka, R. "Hedging techniques in commodity risk management". Agricultural Economics- Czech 60(4), pp. 174-182 (2014).

59. Yang, L., Ruihong, T., Kebing, C. "Call, put and bidirectional option contracts in agriculture supply chains with sales effort”. Applied Mathematical Modelling 47, pp. 1-16 (2017).

60. Park, J.H., Kazaz, B., Webster, S., "Risk mitigation of production hedging". Production and Operations Management 26(7), pp. 1299-1314 (2017).

61. Kouvelis, P., Wu, X., and Xiao, Y. "Cash hedging in a supply chain”. Management Science 65(9), pp. 3449-3947 (2018).

62. Kouvelis, P., Pang, Z., Ding, Q., "Integrated commodity inventory management and financial hedging: a dynamic mean-variance analysis". Production and Operations Management 27(6), pp. 1052-1073. 
63. Liu, Z., Wang, J., "Supply chain network equilibrium with strategic financial hedging using futures”. European Journal of Operation Research 272(1), pp. 962-978 (2018).

64. Hu, R., Xiao, Y., and Jiang, C. "Jet fuel hedging, operational fuel efficiency improvement and carbon tax". Transport Research Part B: Methodological 116, pp. 103-123 (2018).

65. Hainaut, D. "Hedging of crop harvest with derivatives on temperature". Insurance: Mathematics and Economics 84, pp. 98-114 (2019).

66. March, B., Zavanella, L., Zanoni, S., "Joint economic lot size models with warehouse financing and financial contracts for hedging stocks under different coordination policies". Journal of Business Economics 90, pp. 1147-1169 (2020).

67. Tsao, Y., Raj, P., and Yu., V. "Product substitution in different weights and brands considering customer segmentation and panic buying behaviour". Industrial Marketing Management 77, pp. 209-220 (2019).

68. Ojha, D., Sahin, F., Shockley, J., and Sridharan, S. V. "Is there a performance trade off in managing order fulfilment and the bullwhip effect in supply chains? The role of information sharing and information type". International Journal of production economics 208, pp. 529543 (2019).

69. Raghunathan, S., Tang, C. S., Yue, X. "Bullwhip effect of multiple products with interdependent product demands". International Series in Operations Research \& Management Science 276, pp. 145-161 (2019).

70. George, J., and Pillai, V.M., “Transfer Function Models of Inventory Policies and Bullwhip Quantification in Supply Chain”. Procedia Technology 25, pp. 1064-1071 (2016).

71. Chen, F., Drezner, Z., Ryan, K., and Simchi-Levi, D. "Quantifying the bullwhip effect in a simple supply chain: The impact of forecasting, lead times, and information". Management Science 46(3), pp. 333-450 (2000).

72. Ozelkan, E. C., and Lim, C. "Conditions of reverse bullwhip effect in pricing for pricesensitive demand functions". Annals of Operations Research, Springer 164(1), pp. 211-227 (2008).

\section{Figure and Table captions:}

Figure 1. retailer's ordering decisions in the second period, (a) retailer uses an optimal order quantity strategy $\left(\mathrm{O}_{2}\right)$, (b) retailer uses hedging strategy $\left(\mathrm{C}_{2}\right)$.

Figure 2. Retailer's ordering process in the second period.

Figure 3. The influence of $r$ and $b$ on $d_{1}, d_{2}^{1}$ and $d_{2}^{2}$ when $\theta_{2}=6$. 
Figure 4. The influence of $c_{o 2}$ on $\triangle B W E$ when $b=4, r=1.5, \theta_{2}=6$.

Figure 5. The influence of $\varphi$ on $\triangle B W E$ when $b=4, r=1.5, \theta_{2}=6, c_{o 2}=20$.

Figure 6. The influence of $r$ on $\triangle B W E$ when $b=4, \theta_{2}=6, c_{o 2}=15$.

Figure 7. The influence of $b$ on $\triangle B W E$ when $c_{o 2}=15, \theta_{2}=6, r=1.5$.

Figure 8. The influence of $\theta_{2}$ on $\triangle B W E$ when $b=4, r=1.5, c_{o 2}=15$.

Figure 9. The influence of $\sigma$ on $\triangle B W E$ when $b=4, r=1.5, \theta_{2}=6, c_{o 2}=15$.

Table 1. Description of scenarios

Table 2. The retailer's optimal order quantity in the second period under decision $j$ and price change $i$

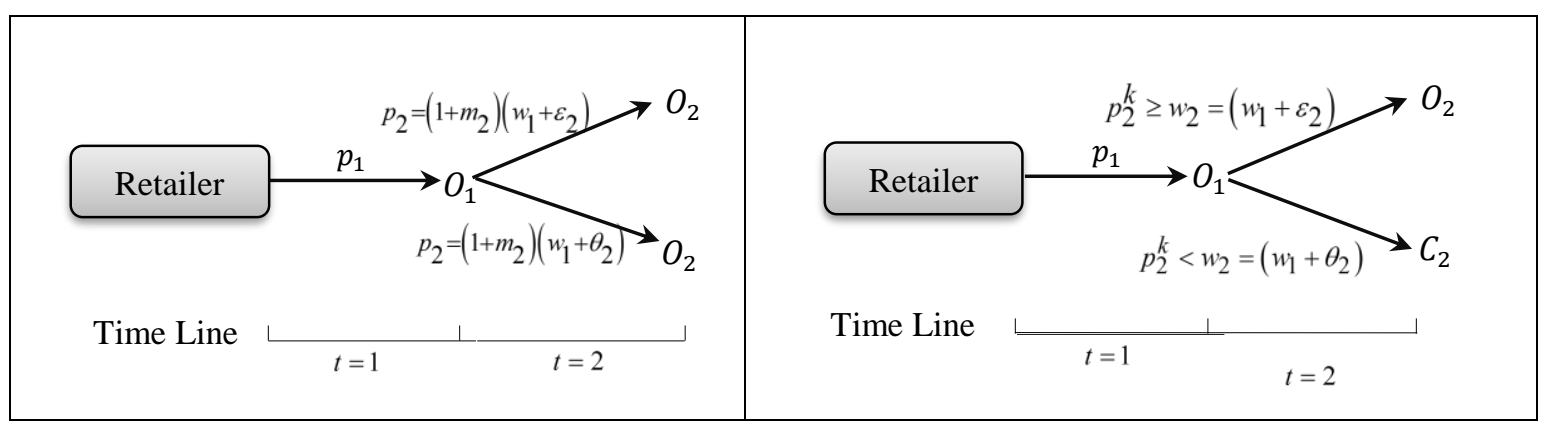

(a)

(b)

Figure 1. 


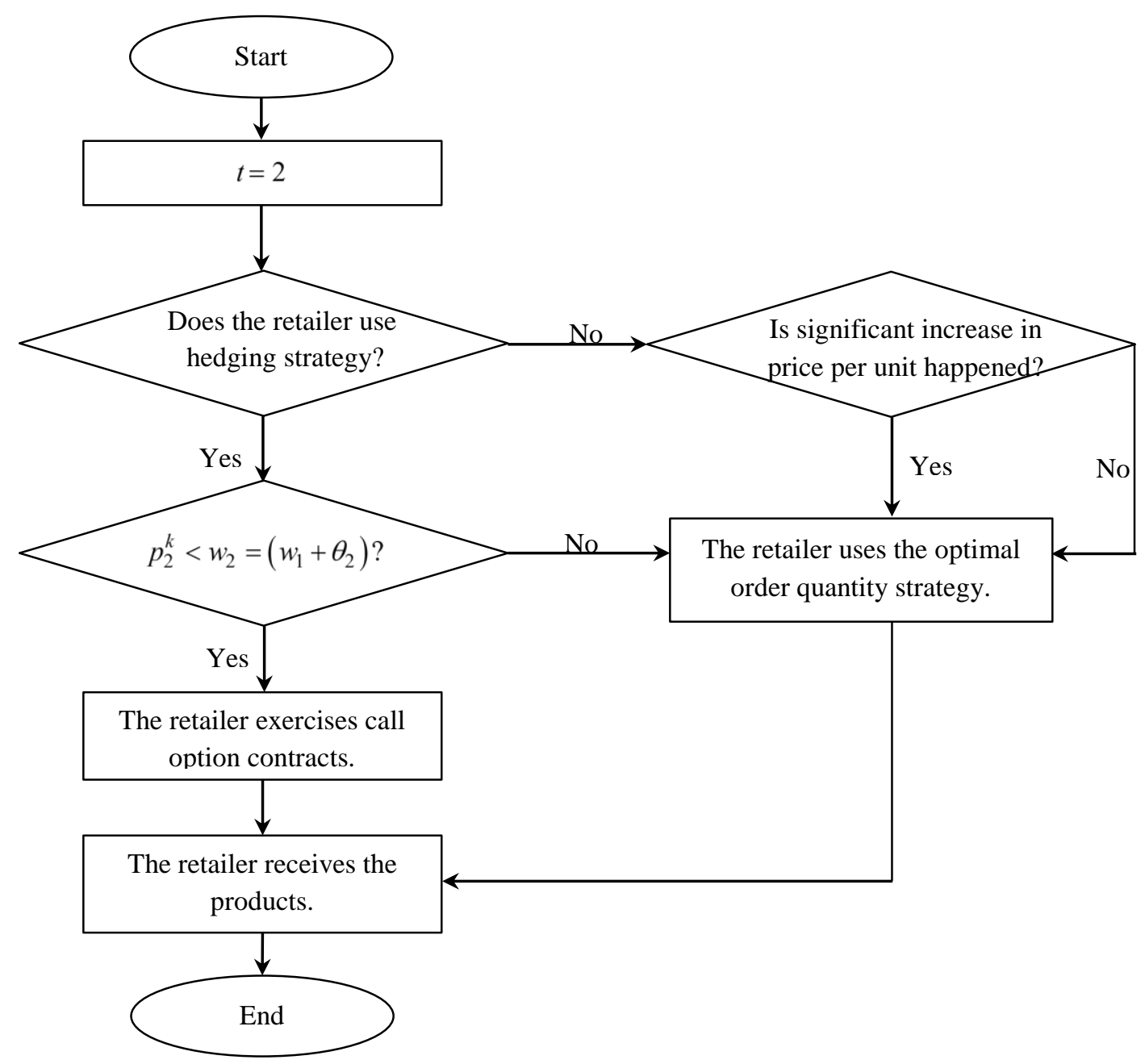

Figure 2.

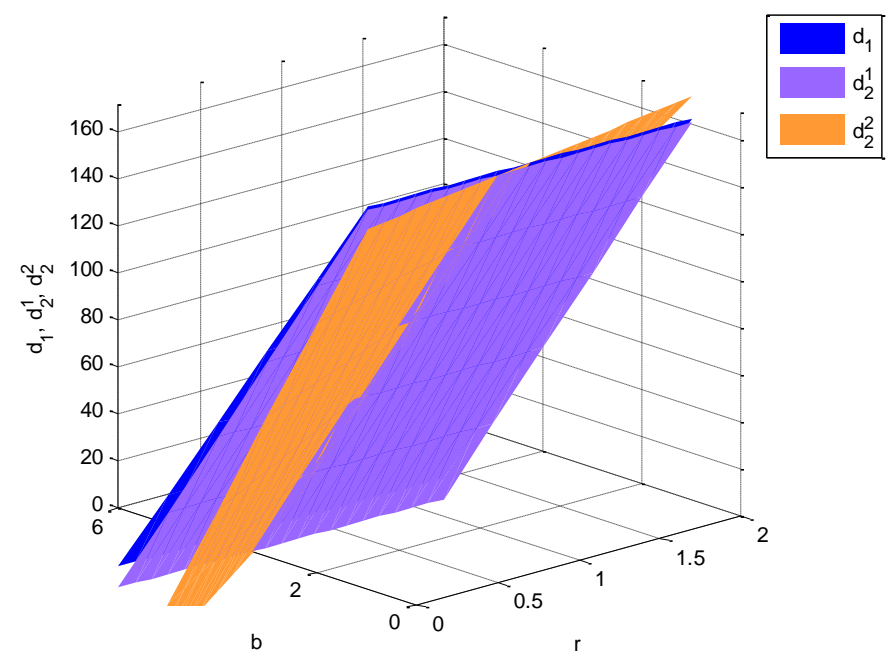

Figure 3. 


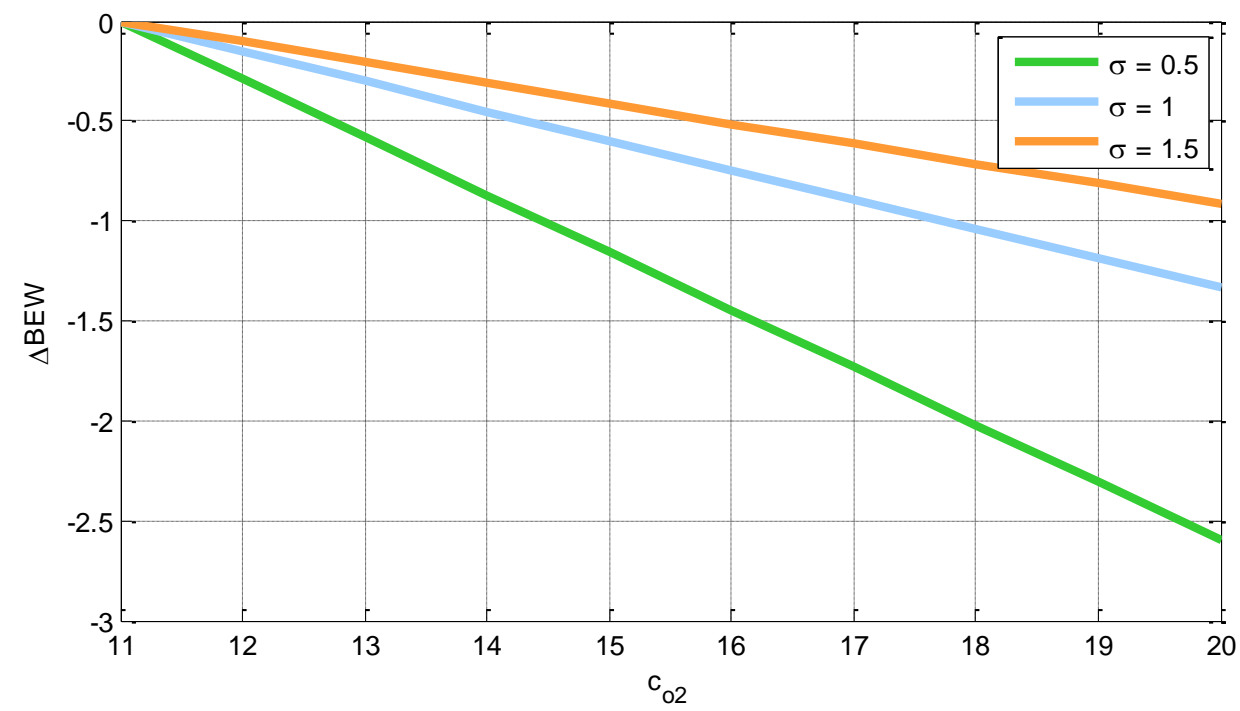

Figure 4.

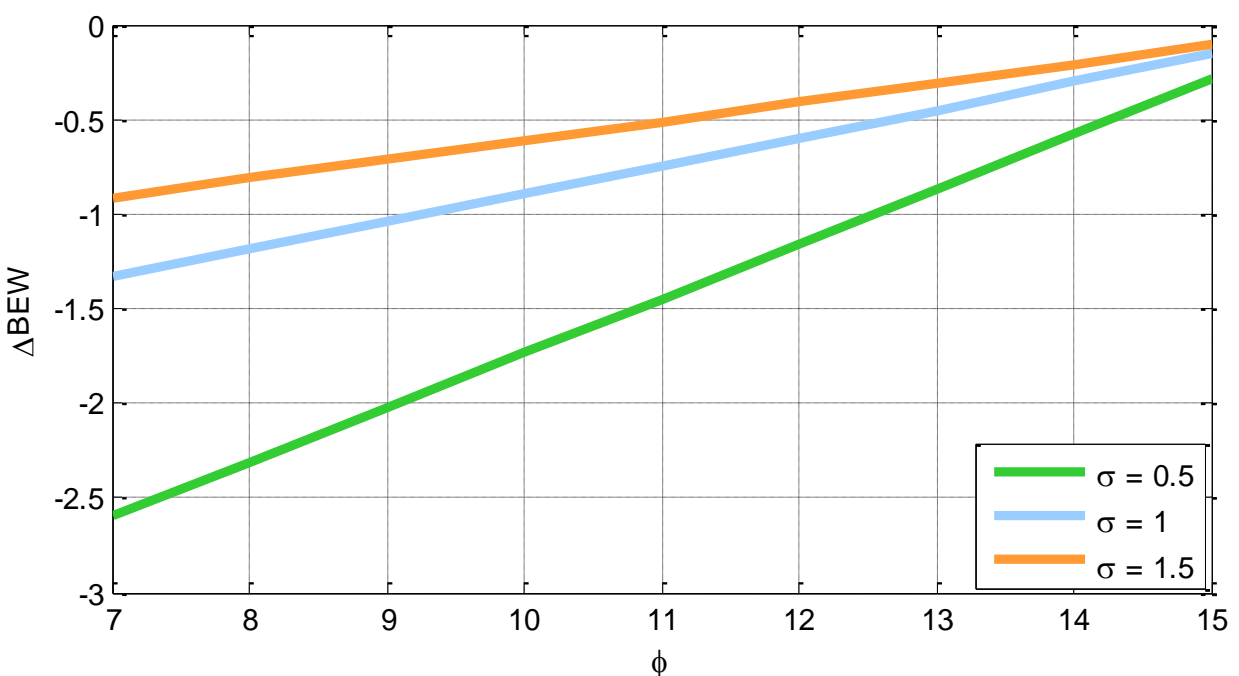

Figure 5.

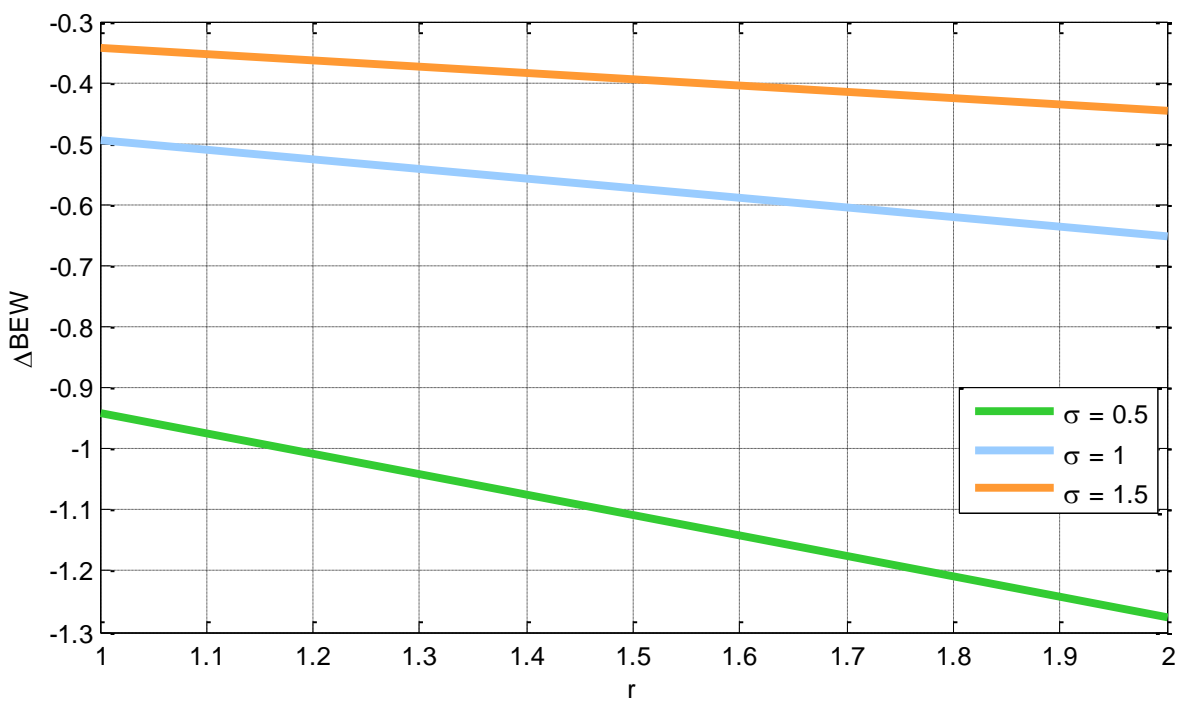

Figure 6. 


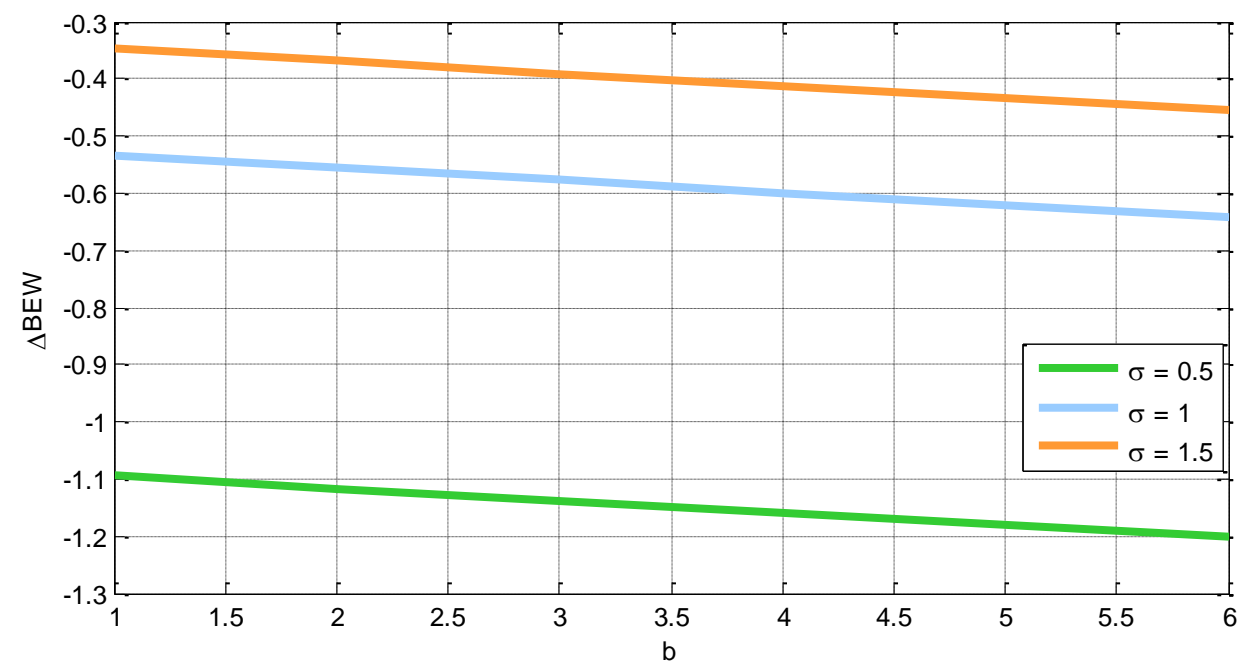

Figure 7.

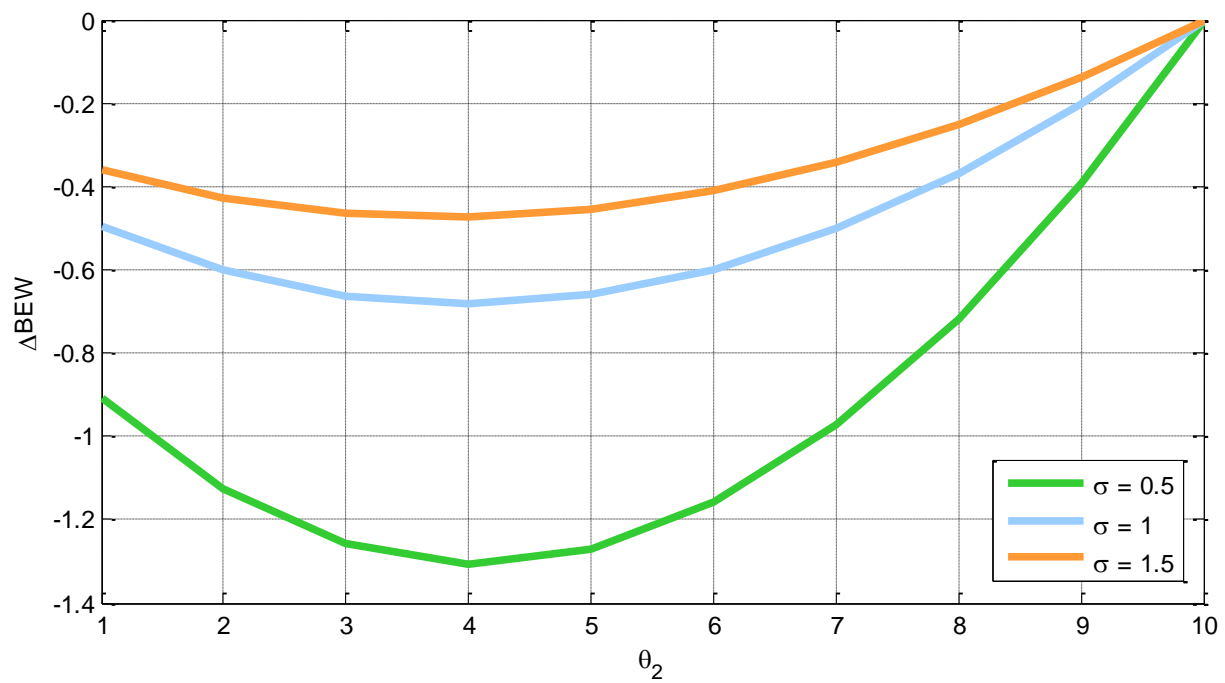

Figure 8.

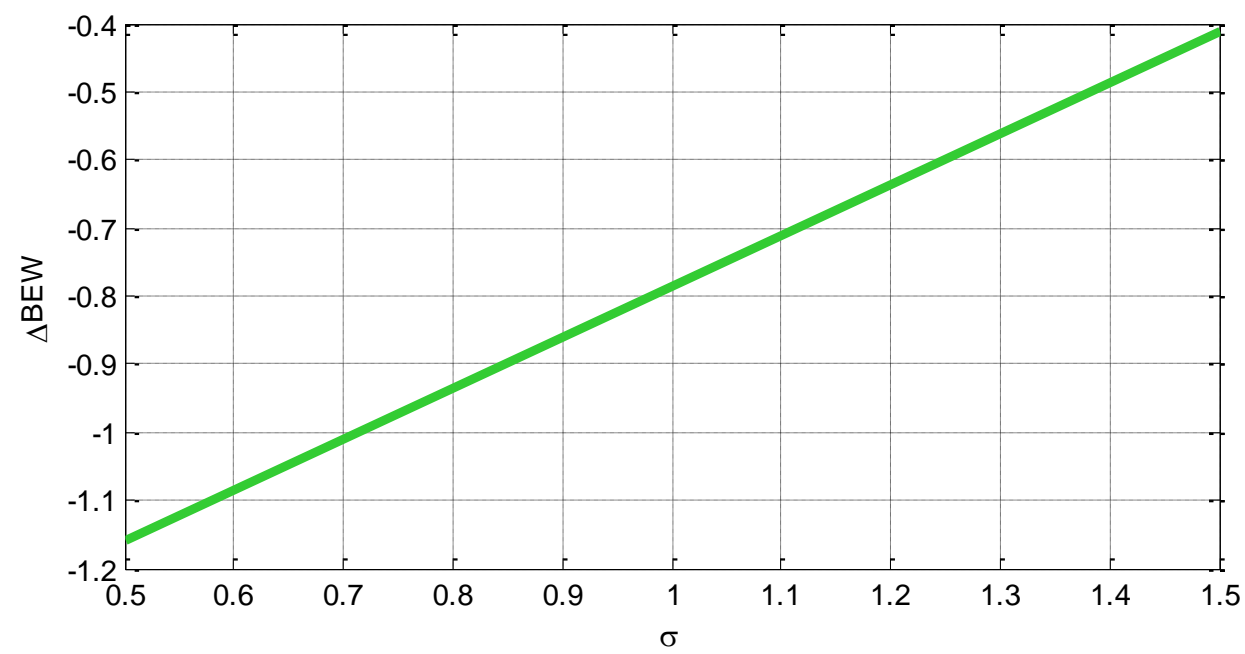




\section{Figure 9.}

Table 1.

\begin{tabular}{clc}
\hline Scenarios & Ordering strategy & Price changes \\
\hline 1 & Optimal order quantity & $w_{2}=w_{1}+\varepsilon_{2}$ \\
2 & & $w_{2}=w_{1}+\theta_{2}$ \\
3 & Hedging & $w_{2}=w_{1}+\varepsilon_{2}$ \\
4 & & $w_{2}=w_{1}+\theta_{2}$ \\
\hline
\end{tabular}

Table 2.

\begin{tabular}{|c|c|}
\hline Scenario & The retailer's optimal order quantity \\
\hline 1 & $\left(q_{2}^{11}\right)^{*}=\mu d_{2}^{1}+\sqrt{2 \pi} \sigma d_{2}^{1}\left[\frac{1}{2}-\frac{w_{2}+c_{2}+h_{2}}{\frac{1}{b}\left(a-d_{2}^{1}\right)+n_{2}}\right]$ \\
\hline 2 & $\left(q_{2}^{21}\right)^{*}=\mu d_{2}^{2}+\sqrt{2 \pi} \sigma d_{2}^{2}\left[\frac{1}{2}-\frac{w_{2}+c_{2}+h_{2}}{\left[\frac{1}{b}\left(a+\left[\left(m_{2}-m_{1}\right) w_{1}+\left(1+m_{2}\right) \theta_{2}\right] r b-d_{2}^{2}\right)\right]+n_{2}}\right.$ \\
\hline 3 & $\left(q_{2}^{12}\right)^{*}=\mu_{d_{2}^{1}}+\sqrt{2 \pi} \sigma d_{2}^{1}\left[\frac{1}{2}-\frac{w_{2}+c_{2}+c_{02}+h_{2}}{\frac{1}{b}\left(a-d_{2}^{1}\right)+n_{2}}\right]$ \\
\hline 4 & $\left(q_{2}^{22}\right)^{*}=\mu d_{2}^{2}+\sqrt{2 \pi} \sigma d_{2}^{2}\left[\frac{1}{2}-\frac{p_{2}^{k}+c_{o 2}+h_{2}}{\frac{1}{b}\left(a+\left[\left(m_{2}-m_{1}\right) w_{1}+\left(1+m_{2}\right) \theta_{2}\right] r b-d_{2}^{2}\right)+n_{2}}\right]$ \\
\hline
\end{tabular}




\section{Biographies}

Kosar Akhavan Chayjan is currently $\mathrm{PhD}$ candidate in the College of Industrial Engineering at University of Tehran. She obtained her MSc degree in Financial Engineering from Kharazmi University, Iran, and her BSc degree in Industrial Engineering from K. N. Toosi University of Technology, Iran. Her research interests include supply chain management, financial markets, financial derivatives, modeling and decision analysis.

Masoud Rabbani is Professor of Industrial Engineering in the School of Industrial and Systems Engineering at the University of Tehran, Iran. He has published more than 250 papers in international journals. His research interests include production planning, maintenance planning, mixed model assembly lines planning, inventory management systems, and applied graph theory.

Jafar Razmi is Professor in the School of Industrial Engineering at the University of Tehran, Tehran, Iran. He teaches undergraduate and graduate courses in industrial engineering, operation management, and MS. He has published over 70 papers in peer-reviewed journals and published more than 70 papers in international conferences. He is in the editorial board of several academic journals. His research interests include supply chain management, operations management, production planning and control, lean manufacturing, and manufacturing measurement and evaluation.

Mohamad Sadegh Sangari is received his $\mathrm{PhD}$ from the University of Tehran, Iran. His research interests include supply chain and operation management (SCM/OM), information technology/systems (IT/IS) management, and customer relationship with specific focus on application of advanced modelling and data analysis approaches, including multivariate data analysis (MVDA) methods as well as optimization and decision analysis. He has published more than 30 papers in peer-reviewed journals and international conferences. He also teaches courses in industrial engineering and MBA and serves a reviewer for several international journals. 


\section{Appendix 1: Proof of Proposition 1}

We substitute formula (12) for $p_{1}$ in formula (10). Thus,

$$
\pi\left(q_{1}^{11}\right)=\left[\frac{1}{b}\left(a-d_{1}\right)\right] S\left(q_{1}^{11}\right)-w_{1} q_{1}^{11}-h_{1} q_{1}^{11}-c_{1} q_{1}^{11}
$$

The expected sales in the first period will be as formula (A.2):

$$
S\left(q_{1}^{11}\right)=\min \left(d_{1}, q_{1}^{11}\right)=q_{1}^{11}-\int_{0}^{q_{1}^{11}} F(x) d x
$$

The expected leftover will be as formula (A.3):

$$
I\left(q_{1}^{11}\right)=E\left(q_{1}^{11}-d_{1}\right)^{+}=q_{1}^{11}-S\left(q_{1}^{11}\right)
$$

Regarding formula (A.1) and taking the first derivative with respect to $q_{1}^{11}$, we obtain formula (A.4).

$$
\frac{\partial \pi\left(q_{1}^{11}\right)}{\partial q_{1}^{11}}=\left[\frac{1}{b}\left(a-d_{1}\right)\right] \frac{\partial S\left(q_{1}^{11}\right)}{\partial q_{1}^{11}}-w_{1}-h_{1}-c_{1}
$$

Result of differentiating $S\left(q_{1}^{11}\right)$ is as follow:

$$
\frac{\partial S\left(q_{1}^{11}\right)}{\partial q_{1}^{11}}=1-F\left(q_{1}^{11}\right)
$$

Regarding formula (A.2), formula (A.5) and taking the second derivative with respect to $q_{1}^{11}$, we obtain formula (A.6).

$$
\frac{\partial^{2} S\left(q_{1}^{11}\right)}{\partial\left(q_{1}^{11}\right)^{2}}=-f\left(q_{1}^{11}\right)
$$

Regarding formula (A.1) and taking the second derivative with respect to $q_{1}^{11}$, we obtain formula (A.7).

$$
\frac{\partial^{2} \pi\left(q_{1}^{11}\right)}{\partial\left(q_{1}^{11}\right)^{2}}=-\left[\frac{1}{b}\left(a-d_{1}\right)\right] f\left(q_{1}^{11}\right)<0
$$

To solve formula (A.1), we consider formula (A.4):

$$
\frac{\partial \pi\left(q_{1}^{11}\right)}{\partial q_{1}^{11}}=0
$$

The retailer's optimal order quantity is given by: 


$$
\left(q_{1}^{11}\right)^{*}=F^{-1}\left(1-\frac{w_{1}+h_{1}+c_{1}}{\frac{1}{b}\left(a-d_{1}\right)}\right)
$$

We consider to $x \sim N\left(\mu, \sigma^{2}\right)$; we will have formula (A.10), formula (A.11), formula (A.12) and formula (A.13).

$$
\begin{aligned}
& F^{-1}(x)=\mu+(\sqrt{2} \sigma) \operatorname{erf}^{-1}(2 x-1) \\
& \operatorname{erf}^{-1}(x)=\sqrt{\pi}\left(\frac{1}{2} x+\frac{1}{24} \pi x^{3}+\frac{7}{960} \pi^{2} x^{5}+\ldots\right) \\
& \operatorname{erf}^{-1}(x) \sim \frac{\sqrt{\pi}}{2} x \\
& \operatorname{erf}^{-1}(2 x-1)=\frac{\sqrt{\pi}}{2}(2 x-1)
\end{aligned}
$$

By substituting (A.13) into formula (A.10), we have formula (A.14).

$$
F^{-1}(x)=\mu+\frac{\sqrt{2 \pi} \sigma}{2}(2 x-1)
$$

By considering formula (A.9) and formula (A.14), we have formula (A.15).

$$
\left(q_{1}^{11}\right)^{*}=\mu_{d_{1}}+\sqrt{2 \pi} \sigma_{d_{1}}\left[\frac{1}{2}-\frac{w_{1}+h_{1}+c_{1}}{\frac{1}{b}\left(a-d_{1}\right)}\right]
$$

This completes the proof.

\section{Appendix 2: Proof of Proposition 2}

We substitute formula (16) for $p_{2}$ in formula (14). Thus,

$$
\pi\left(q_{2}^{11}\right)=\left[\frac{1}{b}\left(a-d_{2}^{1}\right)\right] S\left(q_{2}^{11}\right)-w_{2} q_{2}^{11}-c_{2} q_{2}^{11}-h_{2}\left(q_{2}^{11}+I\left(q_{1}^{11}\right)\right)-n_{2} H\left(q_{2}^{11}\right)
$$

The expected sales will be as formula (B.2):

$$
S\left(q_{2}^{11}\right)=\min \left(d_{2}^{1}, q_{2}^{11}\right)=q_{2}^{11}-\int_{0}^{q_{2}^{11}} F(x) d x
$$

The expected order quantity to the emergency source will be as formula (B.3):

$$
H\left(q_{2}^{11}\right)=H\left(d_{2}^{1}, q_{2}^{11}+I\left(q_{1}^{11}\right)\right)=E\left[d_{2}^{1}-q_{2}^{11}-I\left(q_{1}^{11}\right)\right]^{+}=\mu_{d_{2}^{1}}-S\left(q_{2}^{11}\right)-I\left(q_{1}^{11}\right)
$$

Regarding formula (B.1) and taking the first derivative with respect to $q_{1}^{11}$, we obtain formula (B.4).

$$
\frac{\partial \pi\left(q_{2}^{11}\right)}{\partial q_{2}^{11}}=\left[\frac{1}{b}\left(a-d_{2}^{1}\right)\right] \frac{\partial S\left(q_{2}^{11}\right)}{\partial q_{2}^{11}}-w_{2}-c_{2}-h_{2}-n_{2} \frac{\partial H\left(q_{2}^{11}\right)}{\partial q_{2}^{11}}
$$


Result of differentiating $S\left(q_{2}^{11}\right)$ is as follow:

$$
\frac{\partial S\left(q_{2}^{11}\right)}{\partial q_{2}^{11}}=1-F\left(q_{2}^{11}\right)
$$

Result of differentiating $H\left(q_{2}^{11}\right)$ is as follow:

$$
\frac{\partial H\left(q_{2}^{11}\right)}{\partial q_{2}^{11}}=-\frac{\partial S\left(q_{2}^{11}\right)}{\partial q_{2}^{11}}=F\left(q_{2}^{11}\right)-1
$$

Regarding formula (B.5) and formula (B.6) and taking the second derivative with respect to $q_{2}^{11}$ , we obtain formula (B.7) and formula (B.8).

$$
\begin{aligned}
& \frac{\partial^{2} S\left(q_{2}^{11}\right)}{\partial q_{2}^{11^{2}}}=-f\left(q_{2}^{11}\right) \\
& \frac{\partial^{2} H\left(q_{2}^{11}\right)}{\partial q_{2}^{11^{2}}}=f\left(q_{2}^{11}\right)
\end{aligned}
$$

Regarding formula (B.1) and taking the second derivative with respect to $q_{2}^{11}$, we obtain formula (B.9).

$$
\frac{\partial^{2} \pi\left(q_{2}^{11}\right)}{\partial q_{2}^{11^{2}}}=-\left[\frac{1}{b}\left(a-d_{2}^{1}\right)+n_{2}\right] f\left(q_{2}^{11}\right)<0
$$

Therefore, it is clear that $\pi\left(q_{2}^{11}\right)$ is concave.

To solve formula (B.1), we consider formula (B.4):

$$
\frac{\partial \pi\left(q_{2}^{11}\right)}{\partial q_{2}^{11}}=0
$$

The retailer's optimal order quantity is given by:

$$
\left(q_{2}^{11}\right)^{*}=F^{-1}\left(1-\frac{w_{2}+c_{2}+h_{2}}{\frac{1}{b}\left(a-d_{2}^{1}\right)+n_{2}}\right)
$$

By considering formula (A.14) and formula (B.11), we have formula (B.12).

$$
\left(q_{2}^{11}\right)^{*}=\mu_{d_{2}^{1}}+\sqrt{2 \pi} \sigma_{d_{2}^{1}}\left[\frac{1}{2}-\frac{w_{2}+c_{2}+h_{2}}{\frac{1}{b}\left(a-d_{2}^{1}\right)+n_{2}}\right]
$$


Also, according to formula (16) and $\left(n_{2}<p_{2}\right)$ mentioned in subsection 4.1, the denominator of the fraction of formula (B.12) is not zero. Therefore, the boundary conditions are established. This completes the proof.

\section{Appendix 3: Proof of Proposition 3}

We substitute formula (21) for $p_{2}$ in formula (18). Thus,

$$
\pi\left(q_{2}^{21}\right)=\left[\frac{1}{b}\left(a+\left[\left(m_{2}-m_{1}\right) w_{1}+\left(1+m_{2}\right) \theta_{2}\right] r b-d_{2}^{2}\right)\right] S\left(q_{2}^{21}\right)-w_{2} q_{2}^{21}-c_{2} q_{2}^{21}-h_{2}\left(q_{2}^{21}+I\left(q_{1}^{11}\right)\right)-n_{2} H\left(q_{2}^{21}\right)
$$

The expected sales will be as formula (C.2):

$$
S\left(q_{2}^{21}\right)=\min \left(d_{2}^{2}, q_{2}^{21}\right)=q_{2}^{21}-\int_{0}^{q_{2}^{21}} F(x) d x
$$

The expected order quantity to the emergency source will be as formula (C.3):

$$
H\left(q_{2}^{21}\right)=H\left(d_{2}^{2}, q_{2}^{21}+I\left(q_{1}^{11}\right)\right)=E\left[d_{2}^{1}-q_{2}^{21}-I\left(q_{1}^{11}\right)\right]^{+}=\mu_{d_{2}^{2}}-S\left(q_{2}^{21}\right)-I\left(q_{1}^{11}\right)
$$

Regarding formula (C.1) and taking the first derivative with respect to $q_{2}^{21}$, we obtain formula (C.4).

$$
\frac{\partial \pi\left(q_{2}^{21}\right)}{\partial q_{2}^{21}}=\left[\frac{1}{b}\left(a+\left[\left(m_{2}-m_{1}\right) w_{1}+\left(1+m_{2}\right) \theta_{2}\right] r b-d_{2}^{2}\right)\right] \frac{\partial S\left(q_{2}^{21}\right)}{\partial q_{2}^{21}}-w_{2}-c_{2}-h_{2}-n_{2} \frac{\partial H\left(q_{2}^{21}\right)}{\partial q_{2}^{21}}
$$

Result of differentiating $S\left(q_{2}^{21}\right)$ is as follow:

$$
\frac{\partial S\left(q_{2}^{21}\right)}{\partial q_{2}^{21}}=1-F\left(q_{2}^{21}\right)
$$

Result of differentiating $H\left(q_{2}^{21}\right)$ is as follow:

$$
\frac{\partial H\left(q_{2}^{21}\right)}{\partial q_{2}^{21}}=-\frac{\partial S\left(q_{2}^{21}\right)}{\partial q_{2}^{21}}=F\left(q_{2}^{21}\right)-1
$$

Regarding formula (C.5) and formula (C.6) and taking the second derivative with respect to $q_{2}^{21}$ , we obtain formula (C.7) and formula (C.8).

$$
\begin{aligned}
& \frac{\partial^{2} S\left(q_{2}^{21}\right)}{\partial q_{2}^{21^{2}}}=-f\left(q_{2}^{21}\right) \\
& \frac{\partial^{2} H\left(q_{2}^{21}\right)}{\partial q_{2}^{21^{2}}}=f\left(q_{2}^{21}\right)
\end{aligned}
$$

Regarding formula (C.1) and taking the second derivative with respect to $q_{2}^{21}$, we obtain formula (C.9). 


$$
\frac{\partial^{2} \pi\left(q_{2}^{21}\right)}{\partial q_{2}^{21^{2}}}=-\left[\frac{1}{b}\left(a+\left[\left(m_{2}-m_{1}\right) w_{1}+\left(1+m_{2}\right) \theta_{2}\right] r b-d_{2}^{2}\right)+n_{2}\right] f\left(q_{2}^{21}\right)<0,
$$

Therefore, it is clear that $\pi\left(q_{2}^{21}\right)$ is concave.

To solve formula (C.1), we consider formula (C.4):

$$
\frac{\partial \pi\left(q_{2}^{21}\right)}{\partial q_{2}^{21}}=0
$$

The retailer's optimal order quantity is given by

$$
\left(q_{2}^{21}\right)^{*}=F^{-1}\left(1-\frac{w_{2}+c_{2}+h_{2}}{\left[\frac{1}{b}\left(a+\left[\left(m_{2}-m_{1}\right) w_{1}+\left(1+m_{2}\right) \theta_{2}\right] r b-d_{2}^{2}\right)\right]+n_{2}}\right)
$$

By considering formula (A.14) and formula (C.11), we have formula (C.12).

$$
\left(q_{2}^{21}\right)^{*}=\mu_{d_{2}^{2}}+\sqrt{2 \pi} \sigma_{d_{2}^{2}}\left[\frac{1}{2}-\frac{w_{2}+c_{2}+h_{2}}{\left[\frac{1}{b}\left(a+\left[\left(m_{2}-m_{1}\right) w_{1}+\left(1+m_{2}\right) \theta_{2}\right] r b-d_{2}^{2}\right)\right]+n_{2}}\right]
$$

This completes the proof.

\section{Appendix 4: Proof of Proposition 4}

We substitute formula (25) for $p_{2}$ in formula (23). Thus,

$$
\pi\left(q_{2}^{12}\right)=\left[\frac{1}{b}\left(a-d_{2}^{1}\right)\right] S\left(q_{2}^{12}\right)-w_{2} q_{2}^{12}-c_{2} q_{2}^{12}-c_{o 2} q_{2}^{12}-h_{2}\left(q_{2}^{12}+I\left(q_{1}^{11}\right)\right)-n_{2} H\left(q_{2}^{12}\right)
$$

The expected sales will be as formula (D.2):

$$
S\left(q_{2}^{12}\right)=\min \left(d_{2}^{1}, q_{2}^{12}\right)=q_{2}^{12}-\int_{0}^{q_{2}^{12}} F(x) d x
$$

The expected order quantity to the emergency source will be as formula (D.3):

$$
H\left(q_{2}^{12}\right)=H\left(d_{2}^{1}, q_{2}^{12}+I\left(q_{1}^{11}\right)\right)=E\left[d_{2}^{1}-q_{2}^{12}-I\left(q_{1}^{11}\right)\right]^{+}=\mu_{d_{2}^{1}}-S\left(q_{2}^{12}\right)-I\left(q_{1}^{11}\right)
$$

Regarding formula (D.1) and taking the first derivative with respect to $q_{2}^{12}$, we obtain formula (D.4).

$$
\frac{\partial \pi\left(q_{2}^{12}\right)}{\partial q_{2}^{12}}=\left[\frac{1}{b}\left(a-d_{2}^{1}\right)\right] \frac{\partial S\left(q_{2}^{12}\right)}{\partial q_{2}^{12}}-w_{2}-c_{2}-c_{o 2}-h_{2}-n_{2} \frac{\partial H\left(q_{2}^{12}\right)}{\partial q_{2}^{12}}
$$

Result of differentiating $S\left(q_{2}^{12}\right)$ is as follow: 


$$
\frac{\partial S\left(q_{2}^{12}\right)}{\partial q_{2}^{12}}=1-F\left(q_{2}^{12}\right)
$$

Result of differentiating $H\left(q_{2}^{12}\right)$ is as follow:

$$
\frac{\partial H\left(q_{2}^{12}\right)}{\partial q_{2}^{12}}=-\frac{\partial S\left(q_{2}^{12}\right)}{\partial q_{2}^{12}}=F\left(q_{2}^{12}\right)-1
$$

Regarding formula (D.5) and formula (D.6) and taking the second derivative with respect to $q_{2}^{12}$ , we obtain formula (D.7) and formula (D.8).

$$
\begin{aligned}
& \frac{\partial^{2} S\left(q_{2}^{12}\right)}{\partial q_{2}^{12^{2}}}=-f\left(q_{2}^{12}\right) \\
& \frac{\partial^{2} H\left(q_{2}^{12}\right)}{\partial q_{2}^{12^{2}}}=f\left(q_{2}^{12}\right)
\end{aligned}
$$

Regarding formula (D.1) and taking the second derivative with respect to $q_{2}^{12}$, we obtain formula (D.9).

$$
\frac{\partial^{2} \pi\left(q_{2}^{12}\right)}{\partial q_{2}^{12^{2}}}=-\left[\frac{1}{b}\left(a-d_{2}^{1}\right)+n_{2}\right] f\left(q_{2}^{12}\right)<0
$$

Therefore, it is clear that $\pi\left(q_{2}^{12}\right)$ is concave.

To solve formula (D.1), we consider formula (D.4):

$$
\frac{\partial \pi\left(q_{2}^{12}\right)}{\partial q_{2}^{12}}=0
$$

The retailer's optimal order quantity is given by:

$$
\left(q_{2}^{12}\right)^{*}=F^{-1}\left(1-\frac{w_{2}+c_{2}+c_{o 2}+h_{2}}{\frac{1}{b}\left(a-d_{2}^{1}\right)+n_{2}}\right)
$$

By considering formula (A.14) and formula (D.11), we have formula (D.12).

$$
\left(q_{2}^{12}\right)^{*}=\mu_{d_{2}^{1}}+\sqrt{2 \pi} \sigma_{d_{2}^{1}}\left[\frac{1}{2}-\frac{w_{2}+c_{2}+c_{o 2}+h_{2}}{\frac{1}{b}\left(a-d_{2}^{1}\right)+n_{2}}\right]
$$

Also, according to formula (25) and $\left(n_{2}<p_{2}\right)$ mentioned in subsection 4.1, the denominator of the fraction of formula (D.12) is not zero. Therefore, the boundary conditions are established.

This completes the proof. 


\section{Appendix 5: Proof of Proposition 5}

We substitute formula (30) for $p_{2}$ in formula (27). Thus,

$$
\pi\left(q_{2}^{22}\right)=\left[\frac{1}{b}\left(a+\left[\left(m_{2}-m_{1}\right) w_{1}+\left(1+m_{2}\right) \theta_{2}\right] r b-d_{2}^{2}\right)\right] s\left(q_{2}^{22}\right)-p_{2}^{k} q_{2}^{22}-c_{o 2} q_{2}^{22}-h_{2}\left(q_{2}^{22}+I\left(q_{1}^{11}\right)\right)-n_{2} H\left(q_{2}^{22}\right)
$$

The expected sales will be as formula (E.2):

$$
S\left(q_{2}^{22}\right)=\min \left(d_{2}^{2}, q_{2}^{22}\right)=q_{2}^{22}-\int_{0}^{q_{2}^{22}} F(x) d x
$$

The expected order quantity to the emergency source will be as formula (E.3):

$$
H\left(q_{2}^{22}\right)=H\left(d_{2}^{2}, q_{2}^{22}+I\left(q_{1}^{11}\right)\right)=E\left[d_{2}^{2}-q_{2}^{22}-I\left(q_{1}^{11}\right)\right]^{+}=\mu_{d_{2}^{2}}-S\left(q_{2}^{22}\right)-I\left(q_{1}^{11}\right)
$$

Regarding formula (E.1) and taking the first derivative with respect to $q_{1}^{11}$, we obtain formula (E.4).

$$
\frac{\partial \pi\left(q_{2}^{22}\right)}{\partial q_{2}^{22}}=\left[\frac{1}{b}\left(a+\left[\left(m_{2}-m_{1}\right) w_{1}+\left(1+m_{2}\right) \theta_{2}\right] r b-d_{2}^{2}\right)\right] \frac{\partial S\left(q_{2}^{22}\right)}{\partial q_{2}^{22}}-p_{2}^{k}-c_{O 2}-h_{2}-n_{2} \frac{\partial H\left(q_{2}^{22}\right)}{\partial q_{2}^{22}}
$$

Result of differentiating $S\left(q_{2}^{22}\right)$ is as follow:

$$
\frac{\partial S\left(q_{2}^{22}\right)}{\partial q_{2}^{22}}=1-F\left(q_{2}^{22}\right)
$$

Result of differentiating $H\left(q_{2}^{22}\right)$ is as follow:

$$
\frac{\partial H\left(q_{2}^{22}\right)}{\partial q_{2}^{22}}=-\frac{\partial S\left(q_{2}^{22}\right)}{q_{2}^{22}}=F\left(q_{2}^{22}\right)-1
$$

Regarding formula (E.5) and formula (E.6) and taking the second derivative with respect to $q_{2}^{22}$ , we obtain formula (E.7) and formula (E.8).

$$
\begin{aligned}
& \frac{\partial^{2} S\left(q_{2}^{22}\right)}{\partial q_{2}^{22^{2}}}=-f\left(q_{2}^{22}\right) \\
& \frac{\partial^{2} H\left(q_{2}^{22}\right)}{\partial q_{2}^{22^{2}}}=f\left(q_{2}^{22}\right)
\end{aligned}
$$

Regarding formula (E.1) and taking the second derivative with respect to $q_{2}^{22}$, we obtain formula (E.9).

$$
\frac{\partial^{2} \pi\left(q_{2}^{22}\right)}{\partial q_{2}^{22^{2}}}=-\left[\frac{1}{b}\left(a+\left[\left(m_{2}-m_{1}\right) w_{1}+\left(1+m_{2}\right) \theta_{2}\right] r b-d_{2}^{2}\right)+n_{2}\right] f\left(q_{2}^{22}\right)<0
$$

Therefore, it is clear that $\pi\left(q_{2}^{22}\right)$ is concave.

To solve formula (E.1), we consider formula (E.4): 


$$
\frac{\partial \pi\left(q_{2}^{22}\right)}{\partial q_{2}^{22}}=0
$$

The retailer's optimal order quantity is given by:

$$
\left(q_{2}^{22}\right)^{*}=F^{-1}\left(1-\frac{p_{2}^{k}+c_{o 2}+h_{2}}{\frac{1}{b}\left(a+\left[\left(m_{2}-m_{1}\right) w_{1}+\left(1+m_{2}\right) \theta_{2}\right] r b-d_{2}^{2}\right)+n_{2}}\right)
$$

By considering formula (A.14) and formula (E.11), we have formula (E.12).

$$
\left(q_{2}^{22}\right)^{*}=\mu_{d_{2}^{2}}+\sqrt{2 \pi} \sigma_{d_{2}^{2}}\left[\frac{1}{2}-\frac{p_{2}^{k}+c_{o 2}+h_{2}}{\frac{1}{b}\left(a+\left[\left(m_{2}-m_{1}\right) w_{1}+\left(1+m_{2}\right) \theta_{2}\right] r b-d_{2}^{2}\right)+n_{2}}\right]
$$

This completes the proof.

\section{Appendix 6. Proof of Theorem 1}

$\bar{q}_{q_{1}^{11}, q_{2}^{21}}$ is calculated as follow:

$$
\begin{aligned}
& \bar{q}_{q_{1}^{11}, q_{2}^{21}}=\frac{1}{2}\left(q_{1}^{11}+q_{2}^{21}\right)= \\
& \frac{1}{2}\left[\left(\mu_{d_{1}}+\sqrt{2 \pi} \sigma d_{1}\left[\frac{1}{2}-\frac{w_{1}+h_{1}+c_{1}}{\frac{1}{b}\left(a-d_{1}\right)}\right]\right)+\mu_{d_{2}^{2}}+\sqrt{2 \pi} \sigma d_{2}^{2}\left[\frac{1}{2}-\frac{w_{2}+c_{2}+h_{2}}{\left[\frac{1}{b}\left(a+\left[\left(m_{2}-m_{1}\right) w_{1}+\left(1+m_{2}\right) \theta_{2}\right] r b-d_{2}^{2}\right)\right]+n_{2}}\right]\right]
\end{aligned}
$$

With substituting formula (42) and formula (F.1) in formula (45), we obtain formula (F.2).

$$
\begin{aligned}
& B W E_{q_{1}^{11}, q_{2}^{21}}= \\
& \frac{\frac{1}{2}\left[\left(\mu_{d_{2}^{2}}+\sqrt{2 \pi} \sigma d_{2}^{2}\left[\frac{1}{2}-\frac{w_{2}+c_{2}+h_{2}}{\left.\left[\frac{1}{\left.b\left(a+\left[\left(m_{2}-m_{1}\right) w_{1}+\left(1+m_{2}\right) \theta_{2}\right] r b-d_{2}^{2}\right)\right]+n_{2}}\right]\right)}\right]-\left(\mu_{d_{1}}+\sqrt{2 \pi} \sigma_{d_{1}}\left[\frac{1}{2}-\frac{w_{1}+h_{1}+c_{1}}{\frac{1}{b}\left(a-d_{1}\right)}\right]\right)\right]^{2}\right.}{\left(2 b^{2}+2 r^{2} b^{2}\right) \sigma^{2}}
\end{aligned}
$$

With substituting formula (39), formula (41), formula (43) and formula (44) in formula (F.2), we have formula (F.3) as follow:

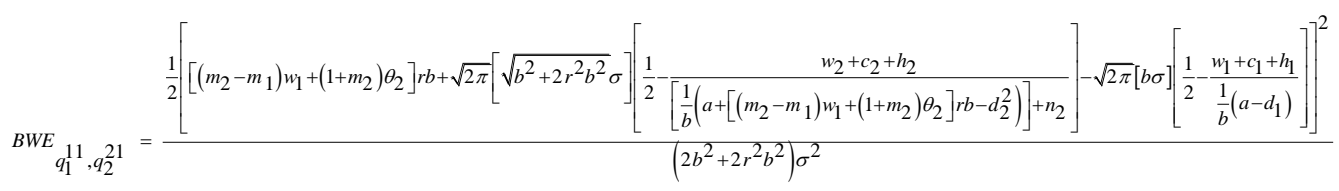

This completes the proof.

\section{Appendix 7. Proof of Proposition 6}


Bullwhip effect exists if formula (G.1) holds.

$$
B W E_{q_{1}^{11}, q_{2}^{21}}>1
$$

With substituting formula (46) in formula (G.1), we have

$$
\begin{aligned}
& \frac{\frac{1}{2}\left[\left[\left(m_{2}-m_{1}\right) w_{1}+\left(1+m_{2}\right) \theta_{2}\right] r b+\sqrt{2 \pi}\left[\sqrt{b^{2}+2 r^{2} b^{2}} \sigma\right]\left[\frac{1}{2}-\frac{w_{2}+c_{2}+h_{2}}{\left[\frac{1}{b}\left(a+\left[\left(m_{2}-m_{1}\right) w_{1}+\left(1+m_{2}\right) \theta_{2}\right] r b-d_{2}^{2}\right)\right]}\right]-\sqrt{2 \pi}[b \sigma]\left[\frac{1}{2}-\frac{w_{1}+c_{1}+h_{1}}{\frac{1}{b}\left(a-d_{1}\right)}\right]\right]^{2}}{\left(2 b^{2}+2 r^{2} b^{2}\right) \sigma^{2}}>1 \\
& \frac{1}{2\left(2 b^{2}+2 r^{2} b^{2}\right) \sigma^{2}}\left[\left[\left(m_{2}-m_{1}\right) w_{1}+\left(1+m_{2}\right) \theta_{2}\right] r b+\sqrt{2 \pi}\left[\sqrt{b^{2}+2 r^{2} b^{2} \sigma}\right]\left[\frac{1}{\frac{1}{2}} \frac{w_{2}+c_{2}+h_{2}}{\left[\frac{1}{b}\left(a+\left[\left(m_{2}-m_{1}\right) w_{1}+\left(1+m_{2}\right) \theta_{2}\right] r b-d_{2}^{2}\right)\right]+n_{2}}\right]-\sqrt{2 \pi}[b \sigma]\left[\frac{1}{2}-\frac{w_{1}+c_{1}+h_{1}}{\frac{1}{b}\left(a-d_{1}\right)}\right]\right]^{2}>1 \\
& {\left[\left[\left(m_{2}-m_{1}\right) w_{1}+\left(1+m_{2}\right) \theta_{2}\right] r b+\sqrt{2 \pi}\left[\sqrt{b^{2}+2 r^{2} b^{2}} \sigma\right]\left[\frac{1}{2}-\frac{w_{2}+c_{2}+h_{2}}{\left[\frac{1}{b}\left(a+\left[\left(m_{2}-m_{1}\right) w_{1}+\left(1+m_{2}\right) \theta_{2}\right] r b-d_{2}^{2}\right)\right]+n_{2}}\right]-\sqrt{2 \pi}[b \sigma]\left[\frac{1}{2}-\frac{w_{1}+c_{1}+h_{1}}{\frac{1}{b}\left(a-d_{1}\right)}\right]\right]^{2}>2\left(2 b^{2}+2 r^{2} b^{2}\right) \sigma^{2}} \\
& {\left[\left[\left(m_{2}-m_{1}\right) w_{1}+\left(1+m_{2}\right) \theta_{2}\right] r b+\sqrt{2 \pi}\left[\sqrt{b^{2}+2 r^{2} b^{2}} \sigma\right]\left[\frac{1}{\frac{1}{2}-}\left[\frac{1}{\left[\frac{1}{b}\left(a+\left[\left(m_{2}-m_{1}\right) w_{1}+\left(1+m_{2}\right) \theta_{2}\right] r b-d_{2}^{2}\right)\right]+n_{2}}\right]-\sqrt{2 \pi}[b \sigma]\left[\frac{1}{2}-\frac{w_{1}+c_{1}+m_{1}}{\frac{1}{b}\left(a-d_{1}\right)}\right]\right]^{2}-2\left(2 b^{2}+2 r^{2} b^{2}\right) \sigma^{2}>0\right.}
\end{aligned}
$$

We know if $x^{2}>y^{2}$, then $x>y$ and $-x<-y$. Also, We consider $\frac{\sqrt{2 \pi}}{2} \square 1.25, \sqrt{2 \pi} \square 2.5$.

Therefore, we have formula (G.6) and formula (G.7).

$$
\begin{aligned}
& {\left[\left(m_{2}-m_{1}\right) w_{1}+\left(1+m_{2}\right) \theta_{2}\right] r b+1.25\left[\sqrt{b^{2}+2 r^{2} b^{2}} \sigma\right]-2.5\left[\sqrt{b^{2}+2 r^{2} b^{2}} \sigma\right]\left[\frac{w_{2}+c_{2}+h_{2}}{\left[\frac{1}{b}\left(a+\left[\left(m_{2}-m_{1}\right) w_{1}+\left(1+m_{2}\right) \theta_{2}\right] r b-d_{2}^{2}\right)\right]+n_{2}}\right]-1.25[b \sigma]+} \\
& 2.5[b \sigma]\left[\frac{w_{1}+c_{1}+b_{1}}{\frac{1}{b}\left(a-d_{1}\right)}\right]>\sqrt{2\left(2 b^{2}+2 r^{2} b^{2}\right)} \sigma \\
& -\left[\begin{array}{l}
{\left[\left(m_{2}-m_{1}\right) w_{1}+\left(1+m_{2}\right) \theta_{2}\right] r b+1.25\left[\sqrt{b^{2}+2 r^{2} b^{2}} \sigma\right]-2.5\left[\sqrt{b^{2}+2 r^{2} b^{2} \sigma} \sigma\right]\left[\frac{1}{\left[\frac{1}{b}\left(a+\left[\left(m_{2}-m_{1}\right) w_{1}+\left(1+m_{2}\right) \theta_{2}\right] r b-d_{2}^{2}\right)\right]+n_{2}}\right]-1.25[b \sigma]+} \\
2.5[b \sigma]\left[\frac{w_{1}+c_{1}+h_{1}}{\frac{1}{b}\left(a-d_{1}\right)}\right]
\end{array}\right]<-\left[\sqrt{2\left(2 b^{2}+2 r^{2} b^{2}\right)} \sigma\right]
\end{aligned}
$$

After simplification, we have formula (G.8).

$$
\begin{aligned}
& {\left[\left(m_{2}-m_{1}\right) w_{1}+\left(1+m_{2}\right) \theta_{2}\right] r b+1.25\left[\sqrt{b^{2}+2 r^{2} b^{2}} \sigma\right]+2.5[b \sigma]\left[\frac{w_{1}+c_{1}+h_{1}}{\left[\frac{1}{b}\left(a-d_{1}\right)\right]}\right]>} \\
& 2.5\left[\sqrt{b^{2}+2 r^{2} b^{2}} \sigma\right]\left[\frac{w_{2}+c_{2}+h_{2}}{\left[\frac{1}{b}\left(a+\left[\left(m_{2}-m_{1}\right) w_{1}+\left(1+m_{2}\right) \theta_{2}\right] r b-d_{2}^{2}\right)\right]+n_{2}}\right]+1.25[b \sigma]+\sqrt{2\left(2 b^{2}+2 r^{2} b^{2}\right)} \sigma
\end{aligned}
$$

Bullwhip effect exists (i.e. $B W E_{q_{1}^{11}, q_{2}^{21}}>1$ ) if formula (G.8) hold.

This completes the proof.

\section{Appendix 8. Proof of Theorem 2}


$\bar{q}_{q_{1}^{11}, q_{2}^{22}}$ is calculated as follow:

$$
\bar{q}_{q_{1}^{11}, q_{2}^{22}}=\frac{1}{2}\left(q_{1}^{11}+q_{2}^{22}\right)=\frac{1}{2}\left[\left(\mu_{d_{1}}+\sqrt{2 \pi} \sigma_{d_{1}}\left[\frac{1}{2}-\frac{w_{1}+h_{1}+c_{1}}{\frac{1}{b}\left(a-d_{1}\right)}\right]\right)+\mu_{d_{2}^{2}+\sqrt{2 \pi} \sigma} d_{2}^{2}\left[\frac{1}{2}-\frac{p_{2}^{k}+c_{22}+h_{2}}{\left[\frac{1}{b}\left(a+\left[\left(m_{2}-m_{1}\right) w_{1}+\left(1+m_{2}\right) \theta_{2}\right] r b-d_{2}^{2}\right)\right]+n_{2}}\right]\right]
$$

With substituting formula (42) and formula (H.1) in formula (48), we obtain formula (H.2).

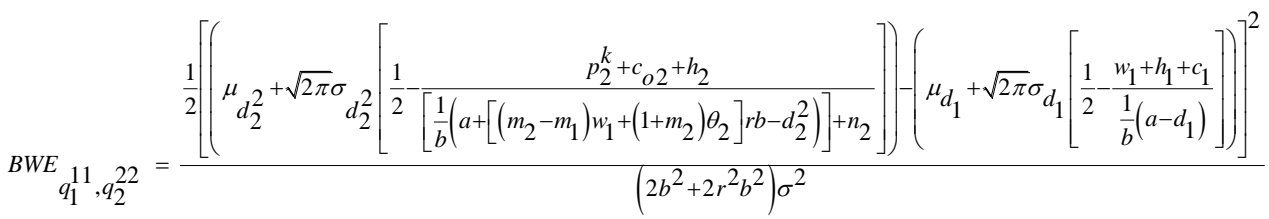

With substituting formula (39), formula (41), formula (43) and formula (44) in formula (H.2), we have formula (H.3) as follow:

$$
{ }_{{ }^{\prime}}{ }_{q_{1}^{11}, q_{2}^{22}}=\frac{\frac{1}{2}\left[\left[\left(m_{2}-m_{1}\right) w_{1}+\left(1+m_{2}\right) \theta_{2}\right] r b+\sqrt{2 \pi}\left[\sqrt{b^{2}+2 r^{2} b^{2}} \sigma\right]\left[\frac{1}{2}-\frac{p_{2}^{k}+c_{o 2}+h_{2}}{\left[\frac{1}{b}\left(a+\left[\left(m_{2}-m_{1}\right) w_{1}+\left(1+m_{2}\right) \theta_{2}\right] r b-d_{2}^{2}\right)\right]+n_{2}}\right]-\sqrt{2 \pi}[b \sigma]\left[\frac{1}{2}-\frac{w_{1}+c_{1}+h_{1}}{\frac{1}{b}\left(a-d_{1}\right)}\right]\right]^{2}}{\left(2 b^{2}+2 r^{2} b^{2}\right) \sigma^{2}}
$$

This completes the proof.

\section{Appendix 9. Proof of Proposition 7}

Bullwhip effect exists if formula (I.1) holds.

$$
B W E_{q_{1}^{11}, q_{2}^{22}}>1
$$

With substituting formula (49) in formula (I.1), we have

$$
\frac{\frac{1}{2}\left[\left[\left(m_{2}-m_{1}\right) w_{1}+\left(1+m_{2}\right) \theta_{2}\right] r b+\sqrt{2 \pi}\left[\sqrt{b^{2}+2 r^{2} b^{2}} \sigma\right]\left[\frac{1}{2}-\frac{p_{2}^{k}+c_{o 2}+h_{2}}{\left[\frac{1}{b}\left(a+\left[\left(m_{2}-m_{1}\right) w_{1}+\left(1+m_{2}\right) \theta_{2}\right] r b-d_{2}^{2}\right)\right]+n_{2}}\right]-\sqrt{2 \pi}[b \sigma]\left[\frac{1}{2}-\frac{w_{1}+c_{1}+h_{1}}{\frac{1}{b}\left(a-d_{1}\right)}\right]\right]^{2}}{\left(2 b^{2}+2 r^{2} b^{2}\right) \sigma^{2}}>1
$$

$$
\begin{aligned}
& \frac{1}{2\left(2 b^{2}+2 r^{2} b^{2}\right) \sigma^{2}}\left[\left[\left(m_{2}-m_{1}\right) w_{1}+\left(1+m_{2}\right) \theta_{2}\right] r b+\sqrt{2 \pi}\left[\sqrt{b^{2}+2 r^{2} b^{2}} \sigma\right]\left[\frac{1}{2}-\frac{p_{2}^{k}+c_{02}+h_{2}}{\left[\frac{1}{b}\left(a+\left[\left(m_{2}-m_{1}\right) w_{1}+\left(1+m_{2}\right) \theta_{2}\right] r b-d_{2}^{2}\right)\right]+n_{2}}\right]-\sqrt{2 \pi}[b \sigma]\left[\frac{1}{2}-\frac{w_{1}+c_{1}+h_{1}}{\frac{1}{b}\left(a-d_{1}\right)}\right]\right]^{2}>1 \\
& {\left[\left[\left(m_{2}-m_{1}\right) w_{1}+\left(1+m_{2}\right) \theta_{2}\right] r b+\sqrt{2 \pi}\left[\sqrt{b^{2}+2 r^{2} b^{2}} \sigma\right]\left[\frac{1}{2}-\frac{p_{2}^{k}+c_{o 2}+h_{2}}{\left[\frac{1}{b}\left(a+\left[\left(m_{2}-m_{1}\right) w_{1}+\left(1+m_{2}\right) \theta_{2}\right] r b-d_{2}^{2}\right)\right]+n_{2}}\right]-\sqrt{2 \pi}[b \sigma]\left[\frac{1}{2}-\frac{w_{1}+c_{1}+h_{1}}{\frac{1}{b}\left(a-d_{1}\right)}\right]\right]^{2}>2\left(2 b^{2}+2 r^{2} b^{2}\right) \sigma^{2}} \\
& {\left[\left[\left(m_{2}-m_{1}\right) w_{1}+\left(1+m_{2}\right) \theta_{2}\right] r b+\sqrt{2 \pi}\left[\sqrt{b^{2}+2 r^{2} b^{2}} \sigma\right]\left[\frac{1}{\frac{1}{2}-}\left[\frac{1}{b}\left(a+\left[\left(m_{2}-m_{1}\right) w_{1}+\left(1+m_{2}\right) \theta_{2}\right] r b-d_{2}^{2}\right)\right]+n_{2}\right]-\sqrt{2 \pi}[b \sigma]\left[\frac{1}{2}-\frac{w_{1}+c_{1}+h_{1}}{\frac{1}{b}\left(a-d_{1}\right)}\right]\right]^{2}-2\left(2 b^{2}+2 r^{2} b^{2}\right) \sigma^{2}>0}
\end{aligned}
$$

We know if $x^{2}>y^{2}$, then $x>y$ and $-x<-y$. Also, We consider $\frac{\sqrt{2 \pi}}{2} \square 1.25, \sqrt{2 \pi} \square 2.5$. Therefore, we have formula (I.6) and formula (I.7). 


$$
\begin{aligned}
& {\left[\left(m_{2}-m_{1}\right) w_{1}+\left(1+m_{2}\right) \theta_{2}\right] r b+1.25\left[\sqrt{b^{2}+2 r^{2} b^{2}} \sigma\right]-2.5\left[\sqrt{b^{2}+2 r^{2} b^{2}} \sigma\right]\left[\frac{p_{2}^{k}+c_{o 2}+h_{2}}{\left[\frac{1}{b}\left(a+\left[\left(m_{2}-m_{1}\right) w_{1}+\left(1+m_{2}\right) \theta_{2}\right] r b-d_{2}^{2}\right)\right]+n_{2}}\right]-1.25[b \sigma]+} \\
& 2.5[b \sigma]\left[\frac{w_{1}+c_{1}+h_{1}}{\frac{1}{b}\left(a-d_{1}\right)}\right]>\sqrt{2\left(2 b^{2}+2 r^{2} b^{2}\right)} \sigma \\
& -\left[\begin{array}{l}
{\left[\left(m_{2}-m_{1}\right) w_{1}+\left(1+m_{2}\right) \theta_{2}\right] r b+1.25\left[\sqrt{b^{2}+2 r^{2} b^{2}} \sigma\right]-2.5\left[\sqrt{b^{2}+2 r^{2} b^{2}} \sigma\right]} \\
-1.25[b \sigma]+2.5[b \sigma]\left[\frac{w_{1}+c_{1}+h_{1}}{\frac{1}{b}\left(a-d_{1}\right)}\right]
\end{array}\right]
\end{aligned}
$$

After simplification, we have formula (I.8).

$$
\begin{aligned}
& {\left[\left(m_{2}-m_{1}\right) w_{1}+\left(1+m_{2}\right) \theta_{2}\right] r b+1.25\left[\sqrt{b^{2}+2 r^{2} b^{2}} \sigma\right]+2.5[b \sigma]\left[\frac{w_{1}+c_{1}+h_{1}}{\frac{1}{b}\left(a-d_{1}\right)}\right]>2.5\left[\sqrt{b^{2}+2 r^{2} b^{2}} \sigma\right]\left[\frac{p_{2}^{k}+c_{c 2}+h_{2}}{\left[\frac{1}{b}\left(a+\left[\left(m_{2}-m_{1}\right) w_{1}+\left(1+m_{2}\right) \theta_{2}\right] r b-d_{2}^{2}\right)\right]+n_{2}}\right]+} \\
& 1.25[b \sigma]+\sqrt{2\left(2 b^{2}+2 r^{2} b^{2}\right)} \sigma
\end{aligned}
$$

Bullwhip effect exists (i.e. $B W E_{q_{1}^{11}, q_{2}^{22}}>1$ ) if formula (I.8) hold.

This completes the proof.

\section{Appendix 10. Proof of Theorem 3}

From formula (46) and formula (49), we obtain formula (J.1):

$$
\begin{aligned}
& \Delta B W E=B W E_{q_{1}^{11}, q_{2}^{22}}-B W E_{q_{1}^{11}, q_{2}^{21}}= \\
& \frac{\frac{1}{2}\left[\left[\left(m_{2}-m_{1}\right) w_{1}+\left(1+m_{2}\right) \theta_{2}\right] r b+\sqrt{2 \pi}\left[\sqrt{b^{2}+2 r^{2} b^{2} \sigma} \sigma\right]\left[\frac{1}{2}-\frac{p_{2}^{k}+c_{\sigma_{2}}+h_{2}}{\left[\frac{1}{b}\left(a+\left[\left(m_{2}-m_{1}\right) w_{1}+\left(1+m_{2}\right) \theta_{2}\right] r b-d_{2}^{2}\right)\right]+n_{2}}\right]-\sqrt{2 \pi}[b \sigma]\left[\frac{1}{2}-\frac{w_{1}+c_{1}+h_{1}}{\frac{1}{b}\left(a-d_{1}\right)}\right]\right]^{2}}{\left(2 b^{2}+2 r^{2} b^{2}\right) \sigma^{2}}- \\
& \frac{\frac{1}{2}\left[\left[\left(m_{2}-m_{1}\right) w_{1}+\left(1+m_{2}\right) \theta_{2}\right] r b+\sqrt{2 \pi}\left[\sqrt{b^{2}+2 r^{2} b^{2} \sigma} \sigma\right]\left[\frac{1}{2}-\frac{1}{\left[\frac{1}{b}\left(a+\left[\left(m_{2}-m_{1}\right) w_{1}+\left(1+m_{2}\right) \theta_{2}\right] r b-d_{2}^{2}\right)\right]+n_{2}}\right]-\sqrt{2 \pi}[b \sigma]\left[\frac{1}{2}-\frac{w_{1}+c_{1}+h_{1}}{\frac{1}{b}\left(a-d_{1}\right)}\right]\right]^{2}}{\left(2 b^{2}+2 r^{2} b^{2}\right) \sigma^{2}}
\end{aligned}
$$

To prove Theorem 3, we need to indicate that $\triangle B W E<0$.

According to formula (13), formula (22), formula (32), formula (39) and formula (41), we have formula (J.2) and formula (J.3).

$$
\begin{aligned}
& \frac{1}{\sqrt{2\left(2 b^{2}+2 r^{2} b^{2}\right) \sigma}}\left[\left[\left(m_{2}-m_{1}\right) w_{1}+\left(1+m_{2}\right) \theta_{2}\right] r b+\sqrt{2 \pi}\left[\sqrt{b^{2}+2 r^{2} b^{2} \sigma}\right]\left[\frac{1}{2}-\frac{1}{\left[\frac{1}{b}\left(a+\left[\left(m_{2}-m_{1}\right) w_{1}+\left(1+m_{2}\right) \theta_{2}\right] r b-d_{2}^{2}\right)\right]+n_{2}}\right]-\sqrt{2 \pi}[b \sigma]\left[\frac{1}{2}-\frac{w_{1}+h_{1}+c_{1}}{\frac{1}{b}\left(a-d_{1}\right)}\right]\right]>0 \\
& \frac{1}{\sqrt{2\left(2 b^{2}+2 r^{2} b^{2}\right) \sigma}}\left[\left[\left(m_{2}-m_{1}\right) w_{1}+\left(1+m_{2}\right) \theta_{2}\right] r b+\sqrt{2 \pi}\left[\sqrt{b^{2}+2 r^{2} b^{2} \sigma}\right]\left[\frac{1}{2}-\frac{w_{2}+h_{2}+c_{2}}{\left[\frac{1}{b}\left(a+\left[\left(m_{2}-m_{1}\right) w_{1}+\left(1+m_{2}\right) \theta_{2}\right] r b-d_{2}^{2}\right)\right]+n_{2}}\right]-\sqrt{2 \pi}[b \sigma]\left[\frac{1}{2}-\frac{w_{1}+m_{1}+c_{1}}{\frac{1}{b}\left(a-d_{1}\right)}\right]\right]>0
\end{aligned}
$$

We know if $x^{2}-y^{2}<0$ and $x, y>0$, then $x<y$. Therefore, we have formula (J.4). 


$$
\begin{aligned}
& \frac{1}{\sqrt{2\left(2 b^{2}+2 r^{2} b^{2}\right) \sigma}}\left[\left[\left(m_{2}-m_{1}\right) w_{1}+\left(1+m_{2}\right) \theta_{2}\right] r b+\sqrt{2 \pi}\left[\sqrt{b^{2}+2 r^{2} b^{2}} \sigma\right]\left[\frac{1}{\frac{1}{2}}-\frac{p_{2}^{k}+h_{2}+c_{o 2}}{\left[\frac{1}{b}\left(a+\left[\left(m_{2}-m_{1}\right) w_{1}+\left(1+m_{2}\right) \theta_{2}\right] r b-d 2\right)\right]+n_{2}}\right]-\sqrt{2 \pi}[b \sigma]\left[\frac{1}{2}-\frac{w_{1}+h_{1}+c_{1}}{\frac{1}{b}\left(a-d_{1}\right)}\right]\right]< \\
& \left.\frac{1}{\sqrt{2\left(2 b^{2}+2 r^{2} b^{2}\right) \sigma}}\left[\left[\left(m_{2}-m_{1}\right) w_{1}+\left(1+m_{2}\right) \theta_{2}\right] r b+\sqrt{2 \pi}\left[\sqrt{b^{2}+2 r^{2} b^{2} \sigma}\right]\left[\frac{1}{\frac{1}{2}}-\frac{w_{2}+h_{2}+c_{2}}{\left[\frac{1}{b}\left(a+\left[\left(m_{2}-m_{1}\right) w_{1}+\left(1+m_{2}\right) \theta_{2}\right] r b-d_{2}^{2}\right)\right]+n_{2}}\right]-\sqrt{2 \pi}[b \sigma] \frac{1}{2}-\frac{w_{1}+h_{1}+c_{1}}{\frac{1}{b}\left(a-d_{1}\right)}\right]\right]
\end{aligned}
$$

After simplification, formula (J.4) reduces to formula (J.5) and then formula (J.6).

$$
\begin{aligned}
& \frac{w_{2}+c_{2}+h_{2}}{\left[\frac{1}{b}\left(a+\left[\left(m_{2}-m_{1}\right) w_{1}+\left(1+m_{2}\right) \theta_{2}\right] r b-d_{2}^{2}\right)\right]+n_{2}}<\frac{p_{2}^{k}+c_{o 2}+h_{2}}{\left[\frac{1}{b}\left(a+\left[\left(m_{2}-m_{1}\right) w_{1}+\left(1+m_{2}\right) \theta_{2}\right] r b-d_{2}^{2}\right)\right]+n_{2}} \\
& w_{2}+c_{2}+h_{2}<p_{2}^{k}+c_{o 2}+h_{2}
\end{aligned}
$$

As a result, according to the formula (31) and formula (J.6), we obtain formula (J.7).

$$
c_{o 2}>c_{2}+\varphi
$$

With considering formula (J.7), we can prove Theorem 3.

This completes the proof. 